\title{
Multidisciplinary approach to prostatitis
}

\author{
Vittorio Magri ${ }^{1}$, Matteo Boltri ${ }^{2}$, Tommaso Cai ${ }^{3}$, Roberto Colombo ${ }^{4}$, Salvatore Cuzzocrea ${ }^{5}$, \\ Pieter De Visschere ${ }^{6}$, Rosanna Giuberti ${ }^{7}$, Clara Maria Granatieri ${ }^{1}$, Maria Agnese Latino ${ }^{9}$, \\ Gaetano Larganà ${ }^{9}$, Christian Leli ${ }^{10}$, Giorgio Maierna ${ }^{1}$, Valentina Marchese ${ }^{11}$, Elisabetta Massa ${ }^{1}$,
} Alberto Matteelli ${ }^{11}$, Emanuele Montanari ${ }^{12}$, Giuseppe Morgia ${ }^{9}$, Kurt G. Naber ${ }^{13}$, Vaia Papadouli ${ }^{14}$, Gianpaolo Perletti ${ }^{15}$, NeKtaria ReKleiti ${ }^{14}$, Giorgio I. Russo ${ }^{9}$, Alessandra Sensini ${ }^{8}$, Konstantinos Stamatiou ${ }^{14}$, Alberto Trinchieri ${ }^{16}$, Florian ME Wagenlehner ${ }^{17}$

${ }^{1}$ ASST Nord Milano, Italy;

${ }^{2}$ Urology Medical School, University of Trieste, Trieste, Italy;

${ }^{3}$ Department of Urology, Santa Chiara Regional Hospital, Trento, Italy;

${ }^{4}$ Synlab Italia, Castenedolo (BS), Italy;

${ }^{5}$ Università degli Studi di Messina, Messina, Italy;

${ }^{6}$ Department of Radiology and Nuclear Medicine, Ghent University Hospital, Ghent, Belgium;

7 SICT Società Idrocolonterapia, Milano, Italy;

${ }^{8}$ Working Group on Sexually Transmitted Infections, Italian Association of Clinical Microbiologists, GLIST-AMCLI, Italy;

${ }^{9}$ Department of Urology, Università degli Studi di Catania, Catania, Italy;

${ }^{10}$ Unit of Microbiology, SS Antonio, Biagio and C. Arrigo Hospital, Alessandria, Italy;

${ }^{11}$ Department of Infectious and Tropical Diseases, University of Brescia, Brescia, Italy;

${ }^{12}$ Department of Urology, IRCCS Ca' Granda Ospedale Maggiore Policlinico - University of Milan, Milan, Italy;

${ }^{13}$ Technical University of Munich, Munich, Germany;

${ }^{14}$ Tzaneio Hospital;

${ }^{15}$ Department of Biotechnology and Life Sciences, Section of Medical and Surgical Sciences, University of Insubria, Varese, Italy;

${ }^{16}$ Urology Unit, Manzoni Hospital, Lecco, Italy;

${ }^{17}$ Clinic for Urology, Pediatric Urology and Andrology, Justus Liebig University Giessen, Germany.

Report of the meeting Prostatitis: A Multidisciplinary Approach (Issues and Controversies), Milano, Italy, 26-27 Oct 2018

\begin{abstract}
Summary The modern clinical research on prostatitis started with the work of Stamey and
\end{abstract} coworkers who developed the basic principles we are still using. They established the segmented culture technique for localizing the infections in the males to the urethra, the bladder, or the prostate and to differentiate the main categories of prostatitis. Such categories with slight modifications are still used according to the NIH classification: acute bacterial prostatitis, chronic bacterial prostatitis, Chronic Pelvic Pain Syndrome (CPPS) and asymptomatic prostatitis. Prostatic inflammation is considered an important factor in influencing both prostatic growth and progression of symptoms of benign prostatic hyperplasia and prostatitis. Chronic inflammation/neuroinflammation is a result of a deregulated acute phase response of the innate immune system affecting surrounding neural tissue at molecular, structural and functional levels. Clinical observations suggest that chronic inflammation correlates with chronic prostatitis/chronic pelvic pain syndrome (CP/CPPS) and benign prostatic hyperplasia (BPH) and an history of clinical chronic prostatitis significantly increases the odds for prostate cancer. The NIHNIDDK classification based on the use of the microbiological 4glasses localization test or simplified 2-glasses test, is currently accepted worldwide. The UPOINT system identifies groups of clinicians with homogeneous clinical presentation and is used to recognize phenotypes to be submitted to specific treatments. The UPOINTS algorithm implemented the original UPOINT adding to the urinary domains $(U)$, psycho-social $(P)$, organspecific $(\mathrm{O})$, infection (I), neurological $(\mathrm{N})$, muscle tension and tenderness $(T)$ a further domain related to sexuality $(S)$. In fact sexual dysfunction (erectile, ejaculatory, libido loss) has been described in 46-92\% of cases with a high impact on the quality of life of patients with CP/CPPS. Prostatic ultrasound represents the most popular imaging test in the work-up of either acute and chronic prostatitis although no specific hypo-hyperechoic pattern has been clearly associated with chronic bacterial prostatitis and CPPS. Use of a digital-processing software to calculate the extension of prostatic calcification area at ultrasound demonstrated a higher percentage of prostatic calcification in patients with chronic bacterial prostatitis. Multiparametric Magnetic Resonance Imaging (mpMRI) is the current state-of-the art imaging modality in the assessment of patients with prostate cancer although a variety of benign conditions, including inflammation, may mimic prostate cancer and act as confounding factors in the discrimination between neoplastic and non-neoplastic lesions. Bacteria can infect prostate gland by: ascending the urethra, reflux of urine into the prostatic ducts, direct inoculation of bacteria through inserted biopsy needles or hematogenous seeding. Enterobacteriaceae are the predominant pathogens in acute and chronic bacterial prostatitis, but an increasing role of Enterococci has been reported. Many strains of these uropathogens exhibit the ability to form biofilm and multidrug-resistance. Sexually Transmitted Infections (STI) agents, in particular Chlamydia trachomatis and Mycoplasma genitalium, have been also considered as causative pathogens of chronic bacterial prostatitis. On the contrary the effective role in genital diseases of other "genital mycoplasmas" is still a much debated issue. Sexually Transmitted Infections agents should be investigated by molecular methods in both patient and sexual partner. "Next generation" investigations, such as cytokine analysis, cytological typing of immune cells could help stratifying the immune response. Epigenetic dysregula- 
tion of inflammatory factors should be investigated according to systemic and compartment-specific signals. The search for biomarkers should also include evaluation of hormonal pathways, as measurement of estrogen levels in semen. Antimicrobials are the first line agents for the treatment of bacterial prostatitis. The success of antimicrobial treatment depends on the antibacterial activity and the pharmacokinetic characteristics of the drug which must reach high concentrations in prostate secretion and prostate tissue. Acute bacterial prostatitis can be a serious infection with a potential risk for urosepsis

For iInitial treatment of severely ill patients, intravenous administration of high doses of bactericidal antimicrobials, such as broad-spectrum penicillins, third-generation

cephalosporins or fluoroquinolones, is recommended in combination with an aminoglycoside. Use of piperacillin-tazobactam and meropenem is justified in presence of multiresistant gramnegative pathogens. The antibiotic treatment of chronic prostatitis is currently based on the use of fluoroquinolones that, given for 2 to 4 weeks, cured about $70 \%$ of men with chronic bacterial prostatitis. For the treatment of Chlamydial prostatitis macrolides were shown to be more effective than fluoroquinolones, whereas no differences were observed in microbiological and clinical efficacy between macrolides and tetracyclines for the treatment of infections caused by intracellular pathogens. Aminoglycosides and fosfomycin could be considered as a therapeutic alternative for the treatment of quinolone resistant prostatitis. Use of alpha-blockers in CP/CPPS patients with urinary symptoms and analgesics +/non steroidal anti-inflammatory drugs (NSAID), in presence of pain demonstrated a reduction of symptoms reduction and an improvement of quality of life, although long term use of NSAID is limited by side effect profile. However, the multimodal therapeutic regimen by contemporary use of alphablockers, antibiotics and anti-inflammatory showed a better control of prostatitis symptoms than single drug treatment. Novel therapeutic substances for the treatment of pain, such as the cannabinoid anandamide would be highly interesting to test. An alternative for the treatment of chronic prostatitis/chronic pelvic pain syndrome is phytotherapy, as primary therapy or in association with other drugs. Quercetin, pollen extract, extract of Serenoa repens and other mixtures of herbal extracts showed a positive effect on symptoms and quality of life without side effects. The association of CP/CPPS with alterations of intestinal function has been described. Diet has its effects on inflammation by regulation of the composition of intestinal flora and direct action on the intestinal cells (sterile inflammation). Intestinal bacteria (microbiota) interacts with food influencing the metabolic, immune and inflammatory response of the organism. The intestinal microbiota has protective function against pathogenic bacteria, metabolic function by synthesis of vitamins, decomposition of bile acids and production of trophic factors (butyrate), and modulation of the intestinal immune system. The alteration of the microbiota is called "dysbiosis" causing invasive intestinal diseases pathologies (leaky gut syndrome and food intolerances, irritable bowel syndrome or chronic inflammatory bowel diseases) and correlating with numerous systemic diseases including acute and chronic prostatitis. Administration of live probiotics bacteria can be used to regulate the balance if intestinal flora. Sessions of hydrocolontherapy can represent an integration to this therapeutic approach. Finally, microbiological examination of sexual partners can offer supplementary information for treatment.

KEY WORDS: Chronic bacterial prostatitis; Chronic pelvic pain syndrome; Inflammation; Antibiotic treatment; Phytotherapy; Dysbiosis.

Submitted 12 Decembrer 2018; Accepted 18 Decembrer 2018

\section{Historical REMARKS}

(Kurt G. Naber)

The modern clinical research on prostatitis started with the work by Meares EM jr. and Stamey TA and coworkers, which Stamey nicely summarized 27 years ago (1). Now we have to see which of their achievements are still valid and which of them have to be reconsidered or even need to be replaced by new findings. In summary, Stamey (1) stated that "Prostatitis" is a common and frustrating problem for the urologist and the general practitioner. Not only is there no generally accepted definition, but there are no clearly established criteria for making the diagnosis, and no definite pathophysiology. Because very few authors have defined prostatitis and almost no two works use the same criteria for inclusion of patients within a study, few comparisons can be made from the findings of one author to those of another. Except for true bacterial prostatitis, it is fair to comment that little more is known about prostatitis than was reported by Hugh H Young and his associates in 1906 (2). Despite this rather pessimistic view, he and his coworkers developed the basic principles we are still using. Together with Meares they established the segmented culture technique for localizing the infections in the males to the urethra, the bladder, or the prostate. Their four glass test results with first voided urine sample, midstram urine sample, expressed prostatic secretion and first voided urine sample after prostate massage were used together with the clinical symptoms to differentiate between the main categories of prostatitis: acute bacterial prostatitis (ABP), chronic bacterial prostatitis (CBP), nonbacterial prostatitis, and prostatodynia. In principle, these categories with slight modifications were also used for the NIH classifications: 1. Acute bacterial prostatitis; 2. Chronic bacterial prostatitis; 3. Chronic Pelvic Pain Syndrom (CPPS); 3a. Inflammatory; 3b. Noninflammatory; and 4. Asymptomatic prostatitis (3). In his review Stamey also presented the principles concerning pharmacokinetics (PK) of antibiotics used for the treatment of acute and chronic bacterial prostatitis and the role of non-ionic diffusion of weak acids and bases across membranes with a $\mathrm{pH}$ gradient (1). He and his coworkers found out, that besides protein binding and lipid solubility the $\mathrm{pH}$ of the prostatic secretion on one side and the isoelectric point of the compound on the other side were playing a major role for drug penetration into the prostatic secretion which was considered crucial at least for the antibacterial therapy of CBP. At that time most studies were performed in a dog model (1). Thereafter, many PK studies were also performed in humans, especially with fluotoquinolones considered the most appropriate antibiotics to treat CBP because of their broad spectrum, including most of the causative pathogens, and because most fluoroquinolones were neither pure acids nor bases, but amphoteric (zwitterionic) drugs with an isoelectric point between the two pKa values (4). Since CPPS on the 
other side was considered a multifactorial disease with many pathophysiological causes a more symptom related approach was finally recommended. For this reason the NIH-CPSI (5) and the UPOINT concept was developed (6). Many other detailed investigations were performed thereafter, but not many had a great impact on the clinical practice so far. Unfortunately the management of CPPS remains still unsatisfactory for the patients as well as for the urologists.

Role of inflammation and infection in the determinism of benign prostatic hyperplasia and prostatitis.

\section{Physiopathological aspects}

\section{(Salvatore Cuzzocrea)}

In the spectrum of benign prostatic syndrome (PBS), chronic prostatitis (CP/CPPS) and benign prostatic hyperplasia (BPH) represent very important pathologies. Prostatic inflammation is considered an important factor in influencing both prostatic growth and progression of symptoms. The common inflammatory/neuroinfalmmatory aspects in $\mathrm{CP} / \mathrm{CPPS}$ and $\mathrm{BPH}$ are represented by reactive astrocytes and activated microglia and involvement of the adaptive immune system, over expression of immune molecules such as chemokines and cytokines and increased oxygen and nitrogen reactive species concentration (ROS/RNS). Chronic inflammation/neuroinflammation is a result of a deregulated acute phase response of the innate immune system effecting surrounding neural tissue on a molecular, structural and functional levels. Clinical observations suggest that chronic inflammation correlates with $\mathrm{CP} / \mathrm{CPPS}$ and $\mathrm{BPH}$, as prostate tissues often have infiltrating lymphocytes and macrophages around glandular elements. The principal therapeutics for treatment of an enlarged prostate are $\alpha$-blockers and $5 \alpha$-reductase inhibitors (5ARIs). Alpha-blockers are often used as first-line therapy, as they relax muscles in the prostate and around the neck of the bladder and facilitate passage of urine but cannot reduce an enlarged prostate; in addition, these agents have side-effects such as first dose syncope, dizziness, tachycardia, hypotension, headache, asthenia, rhinitis and ejaculatory dysfunction. Moreover, cannabinoids have been demonstrated to exert an important role in the resolution of inflammation via multiple mechanisms. In the light of the above, we designed a study to evaluate the anandamide congener $\mathrm{N}$ - palmitoylethanolamide (PEA) and the flavonoid polydatin (PLD), as the formulation $\mathrm{m}(\mathrm{PEA} / \mathrm{PLD})$, in terms of impact on the inflammatory process and oxidative stress in BPH. Recently, literature data reported that PEA, an endogenous fatty acid amide of the Nacylethanolamine family possess analgesic, antiinflammatory and neuroprotective actions, acting at different cellular targets such as immune cells; PEA is classified as a "Food for Special Medical Purposes" by health authorities of the European Union member states. PEA treatment in animals has demonstrated the efficacy and great promise for its use in the treatment of a lot of different inflammatory disorders. Nevertheless, PEA lacks direct antioxidant action to counteract free radical development as well as DNA, protein and lipid damage which are important events occurring in BPH. Polydatin $(3,4,5-$ trihydroxystilbene-3- $\beta$-single-D-glucoside), also known as polygonin, is a polyphenolic phytoalexin with potent anti-oxidative activity that can be isolated from numerous plant species and can be easily synthesized.

Our findings led us to assess the therapeutic effects of oral administration of a composite consisting of comicronized $\mathrm{PEA}+$ polydatin $\mathrm{m}(\mathrm{PEA} / \mathrm{Pol})$ in a model of testosterone-induced benign hyperplasia (BPH) in terms of its therapeutic effects and efficacy as an anti-oxidant and antinflammatory drug (7). The results of our study show, for the first time, that $\mathrm{m}(\mathrm{PEA} / \mathrm{Pol})$ has the ability to decrease prostate weight and DHT production in $\mathrm{BPH}$-induced rats. These effects may be due to the antiinflammatory and apoptotic effects of $\mathrm{m}(\mathrm{PEA} / \mathrm{Pol})$. Preliminary results suggest that $\mathrm{m}(\mathrm{PEA} / \mathrm{Pol})$ may exert therapeutic effect event in a model of CP/CPPS. Accordingly, these results support the hypothesis that $\mathrm{m}(\mathrm{PEA} / \mathrm{Pol})$ should be further explored as a valid candidate for the treatment of $\mathrm{BPH}$.

the I2 value. Pooled analysis resulted in a crude odds ratio of 1.83 , indicating a significant association between a history of prostatitis and prostate cancer (95\% CI: 1.43 to $2.35 ; \mathrm{P}<0.00001$ ) (5). The 1.83 odds ratio could be converted into a significant risk-ratio estimate of 1.63 ( $95 \%$ CI: 1.23 to 2.17 ). The set of pooled data showed considerable heterogeneity $(\mathrm{I} 2=91 \%)$. Sensitivity analysis performed by excluding an extreme outlier decreased heterogeneity $(\mathrm{I} 2=81 \%)$ and resulted in an odds ratio equal to 1.55 (95\% CI: 1.30-1.85,

\section{Prostatitis AND PROState CANCER RISK: META-ANALYSIS (Gianpaolo Perletti)}

Inflammation is a major risk factor for several types of cancer. Conditions like ulcerative colitis, Barrett's esophagus, chronic urothelium inflammation and hepatitis can increase the likelihood of developing malignancies. In the last years, several studies investigated whether a history of clinical chronic prostatitis can be a risk factor for prostate cancer. A meta-analysis of such studies, performed on data published up to July 2012 indicates that clinical prostatitis may be moderately associated with prostate cancer, since the odds ratio between a history of prostatitis and prostate cancer was shown to be 1.64 (95\% CI: 1.36 to 1.98) (8). After year 2012, new quality studies have been performed on over 7000 patients (911). Thus, we deemed necessary to perform an updated meta-analysis to complement the data so far produced, and to further investigate the relationship between prostate cancer and previous exposure to chronic prostatitis. The main outcome of our systematic review was the association between a history of clinical chronic prostatitis (NIH category II or III) and a histologically confirmed diagnosis of prostate cancer of any grade. Out of 2794 de-duplicated records published between year 2000 and January 31 st, 2017 , we retrieved sixteen fulltext articles reporting the data of fifteen case-control studies including a total population of 422943 men. Prostate cancer cases were 13942 (with previous history of prostatitis, $n=1806$ ) and controls were 409001 (with 
previous history of prostatitis, $\mathrm{n}=57203)$. We analyzed binary data by calculating odds ratios and 95\% confidence intervals (95\% CI). We applied a random-effects model to the analysis of pooled data, and heterogeneity was assessed by calculating the $\mathrm{I} 2$ value. Pooled analysis resulted in a crude odds ratio of 1.83, indicating a significant association between a history of prostatitis and prostate cancer (95\% CI: 1.43 to 2.35; $\mathrm{P}<0.00001$ ) (12). The 1.83 odds ratio could be converted into a significant risk-ratio estimate of 1.63 (95\% CI: 1.23 to 2.17). The set of pooled data showed considerable heterogeneity $(I 2=91 \%)$. Sensitivity analysis performed by excluding an extreme outlier decreased heterogeneity (I2 $=81 \%)$ and resulted in an odds ratio equal to 1.55 (95\% CI: 1.30-1.85, P < 0.00001). No significant publication bias was evidenced by the Egger's and Begg's tests for funnel plot asymmetry. The 'trim and fill' method applied to the funnel plot imputed 3 missing studies and the resulting adjusted estimate of the odds ratio was 2.12 (95\% CI: 1.38 to 3.22). Detection bias was virtually present in all included studies, mainly due to the increased probability of prostate cancer detection in prostatitis patients repeatedly subjected to thorough clinical assessments. Five among the included studies reported data assessed in 8015 African-American subjects. A subgroup meta-analysis was attempted, resulting in a non-significant crude odds ratio of 1.59 (95\% CI: 0.71 to $3.57, \mathrm{P}=$ 0.26 ). In conclusion, meta-analysis shows that a history of clinical chronic prostatitis can significantly increase the odds for prostate cancer. The odds ratio of 1.83 , calculated on a larger patient population, is higher than the one reported by Jiang $(\mathrm{OR}=1.6)(8)$, though association between exposure to prostatitis and cancer could not be demonstrated in African-American individuals.

Conversely, a recent meta-analysis showed a clear association in Asian patients (OR = 3.54, 95\% CI: 2.60-4.82) (13) Since - compared with Caucasian men - in men of African descent the prostate cancer incidence is $60 \%$ higher and the mortality rate is up to 3 times greater, new quality studies performed on larger sample sizes are urgently needed to provide unequivocal evidence in this population.

\section{Prostatitis: A Condition Still to Be eXtensively INVESTIGATED}

\section{(Vittorio Magri, Emanuele Montanari)}

Prostatitis is still an enigmatic disease due to the inconsistency of the epidemiological data, the uncertainty etiology, the inadequacy of the diagnosis and the absence of a standardized pharmacological treatment. The term prostatitis, which literally means "inflammation of the prostate", is currently used to describe a set of clinical conditions of uncertain etiology that are not always associated with a clear demonstration of the presence of an inflammatory process and that include painful pelvic symptoms, low urinary tract symptoms and sexual disorders that require differentiated treatment. The prevalence of these symptoms has been estimated at $8 \%$ of the adult male population (14). Patients with prostatitis were initially classified into four groups of acute bacterial prostatitis, chronic bacterial prostatitis, chronic bacterial prostatitis and prostatodynia.
From this classification derived the NIH-NIDDK (National Institute of Health -National Institutes of Diabetes and Digestive and Kidney Diseases) classification (15), which is currently accepted worldwide (Table 1). These classifications are based on the use of the microbiological 4-glasses localization test of Meares-Stamey or of the simplified 2glases test $(16,17)$. The success of this examination requires an appropriate collection of the prostatic secretion after adequate prostatic massage.

The UPOINT system identifies groups of clinicians with homogeneous clinical presentation and is used to recognize phenotypes to be submitted to specific treatments (Table 2) (18). To improve the clinical approach to prostatitis it is crucial to speak a shared language starting from what is already defined in the guidelines of the European Association of Urology (EAU) (19) and other national guidelines like those of the Prostate Expert Reference Group (PERG) of the National Health Service (NHS) (20). The answers of 266 out 1483 (17.9\%) urologists associated to the Società Italiana di Urologia (SIU) who had been sent an e-mail questionnaire to describe the current methods of diagnosis and treatment of chronic prostatitis among Italian urologists showed that a mean of 23 patients with symptoms of prostatitis presented to their clinics in a month. The majority of the respondents still prefers the collection of a narrative clinical history together with the clinical examination whereas the use of validated questionnaires is still not widespread. The NIH-CPSI (National Institute of Health - Chronic Prostatitis Symptom Index) (5) was administered only by $17.29 \%$. The most frequently used laboratory tests are the measurement of PSA and the culture tests of semen and urine. The use of microbiological localization tests is still poorly widespread. The most common instrumental examinations were uroflowmetry and suprapubic ultrasound. Transrectal ultrasound (TRUS) is used only by $10 \%$. An extended protocol, such as that we adopted at our institution, should include: history and physical examination, administration of symptom questionnaires (NIH-CPSI, IPSS, IIEF-15 or -5, PEDT, UPOINT or UPOINTS), microbiological evaluation, prostatic ultrasound and uroflowmetry. In particular we suggest the use of the UPOINTS algorithm that has implemented the original UPOINT proposed by Skoskes (18). To the urinary domains $(\mathrm{U})$, psycho-social $(\mathrm{P})$, organ-specific $(\mathrm{O})$, infection (I), neurological $(\mathrm{N})$, muscle tension and tenderness (T) a further domain related to sexuality (S) was added (21). In fact sexual dysfunction (erectile, ejaculatory, libido loss) has been described in 46-92\% of cases with a high impact on the quality of life of patients with CP/CPPS.

In our experience we observed erectile dysfunction in $49.9 \%$ (although of mild severity in $75 \%$ of cases) and ejaculatory dysfunction in $59.9 \%$ (predominantly burning or ejaculatory pain and premature ejaculation) (22).

According to PERG (20) we also suggest to investigate the presence of irritable bowel syndrome. In fact, in a group of 232 patients we observed the concomitant presence of intestinal disorders (diarrhea or constipation, abdominal pain or bloating) in $69 \%$ and $60.5 \%$ of patients with chronic bacterial prostatitis or pelvic pain syndrome, respectively. Furthermore, the possibility of a sexually transmitted infection starting from a urethral infection that spreads progressively to the prostate and to the accessory 
Table 1.

NIH-NIDDK classification of prostatitis.

\begin{tabular}{|c|c|c|}
\hline Category & Designation & Status of infection \\
\hline I & Acute bacterial prostatitis & Acute infection of prostate \\
\hline$\|$ & Chronic bacterial prostatitis & Recurrent infection of prostate \\
\hline III & Chronic non-bacterial prostatitis/chronic pelvic pain syndrome (CPPS) & No demonstrable infection \\
\hline IIIA & Inflammatory & WBC in semen/EPS/post-prostatic massage urine \\
\hline IIIB & Non-inflammatory & No WBC in semen/EPS/post-prostatic massage urine \\
\hline
\end{tabular}

Table 2.

UPOINTS classification for phenotypic domains (modified by Shokes et al and Magri et al.).

\begin{tabular}{|c|c|c|}
\hline DOMAIN & DIAGNOSIS & TREATMENT \\
\hline Urinary & $\begin{array}{l}\text { CPSI urinary score }>4 \\
\text { Urgency, frequency or nocturia } \\
\text { Post-void residual urine }>100\end{array}$ & $\begin{array}{l}\text { Anticholinergic } \\
\text { Alpha-blockers }\end{array}$ \\
\hline Psychosocial & $\begin{array}{c}\text { Clinical history of depression } \\
\text { Ongoing antidepressant therapy } \\
\text { Evidence of catastrophizing at interview and visits }\end{array}$ & $\begin{array}{c}\text { Counseling } \\
\text { Antidepressant } \\
\text { Referral to psychologist }\end{array}$ \\
\hline Infection & Gram neg or Enterococcus in prostate fluid or 4-glass test & Antibiotics \\
\hline Neurological/systemic & $\begin{array}{l}\text { Pain beyond abdomen or pelvis } \\
\text { Irritable bowel syndrome history } \\
\text { Fibromyalgia history } \\
\text { Chronic fatigue syndrome history }\end{array}$ & $\begin{array}{l}\text { Gabapentinoids } \\
\text { Antidepressants } \\
\text { Specific treatments }\end{array}$ \\
\hline Tenderness (skeletal muscles) & Palpable muscle spasm or trigger points in abdomen and pelvic floor & $\begin{array}{l}\text { Skeletal muscle miorelaxants } \\
\text { Pelvic floor physiotherapy } \\
\text { Physical activity }\end{array}$ \\
\hline Sexual dysfunction & $\begin{array}{c}\text { Erectile dysfunction (IIEF questions } 1-5+15<26 \\
\text { Orgasmic dysfunction evidence (IIEF } 9+10<9 \text { ) } \\
\text { Sexual desire impairment evidence (IIEF questions } 11+12<9 \text { ) }\end{array}$ & PDE5-inhibitors \\
\hline
\end{tabular}

sexual glands has to be considered. Gonococcal infection is infrequent today, but it is still frequent the finding of other sexually transmitted pathogens. In our experience we isolated with the 4-glasses test and/or seminal analysis Chlamydia trachomatis in 26.8-33.6\%, Ureaplasma urealyticum in 56.3-59.7\%, Mycoplasma hominis in 7.3\% and Trichomonas vaginalis in $1.4-1.8 \%$. Finally it is recommended to correctly record the results of treatment on the basis of clinical criteria (NIH-CPSI decrease of at least 4-6 points of the total score or at least $25 \%$ decrease of total score) or of microbiological criteria (eradication, persistence, relapse).

\section{SEXUAL dYSFUNCTION AND CHRONIC PROSTATITIS (Giuseppe Morgia)}

Chronic prostatitis has an important role in men sexual function. Sexual dysfunction is difficulty experienced by an individual or a couple during any stage of a normal sexual activity. It could be sexual desire disorders, sexual arousal disorder, orgasmic disorders, sexual pain disorders. The prevalence of sexual dysfunctions is: $2-40 \%$ for erectile dysfunction, 15-25\% decreased interest or desire, 8-32\% ejaculation dysfunction, 12-19\% orgasm, $17 \%$ dyspareunia. Prostatitis and sexual dysfunction are 2 common diseases, the prevalence of sexual dysfunction among men with CP/CPPS was 62\%. Among chronic bacterial prostatitis symptoms one of the most important symptoms is pain with ejaculation, symptom also present among chronic pelvic pain syndrome symptoms, with erectile dysfunction and premature ejaculation. Ejaculation pain is one of the most important and frequent chronic prostatitis symptoms, in fact in NIH Chronic Prostatitis Symptoms Index there is a question on pain or burning during or after sexual climax. It could be the only manifestation of prostatitis. $24 \%$ of patients have regularly ejaculatory pain, 50\% intermittently and only $26 \%$ of patients with CPPS never experienced ejaculatory pain. There isn't a single cause of post-ejaculatory pain. Seminal infection, ejaculatory duct obstruction (with or without stones), neuromuscular spasm instigated by the muscular constriction of emission, interstitial cystitis could cause pain during ejaculation. Premature ejaculation (PE) is male inability to inhibit ejaculation long enough for the partner to reach orgasm, time before 
ejaculation varied from 1 to 7 minutes after vaginal intromission. PE is an important sexual dysfunction strongly associated to CP/CPPS, chronic bacterial prostatitis and prostatic inflammation. The prevalence of PE among men with CP/CPPS is $40 \%$. The rates of PE and possible $\mathrm{PE}$ assessed with the premature ejaculation diagnostic tool (PEDT) significantly increased with an increase in pelvic pain severity, as assessed by the NIH-CPSI. In the moderate to severe symptom group, $45.0 \%$ men demonstrated PE. In an Italian study of 399 men with symptoms suggesting prostatitis (23), 220 patients (55\%) had ejaculatory dysfunctions, more frequently in patients with bacterial chronic prostatitis with respect to patients with chronic pelvic pain syndrome. In particular Chlamydia trachomatis infection is related to a major incidence of premature ejaculation in patients with CBP (37.2\%), rather than common uropathogen bacteria (11.5\%) (24). The incidence of erectile dysfunction is increasing with age, the prevalence of erectile dysfunction among men with CP/CPPS was 29\%. Aetiology of ED in patients with $\mathrm{CP} / \mathrm{CPPS}$ could be vasculogenic arterial insufficiency and veno-occlusive disease, endocrine, neurogenic, psychogenic. In men with chronic prostatitis there is an arterial stiffness associated with nitric oxide-mediated vascular endothelial dysfunction and 50\% patients have signs of pelvic floor spasm that decrease arterial penile inflow. Hypogonadism is a common finding in men with ED. It has been postulated that sex hormones may also be an important factor in the development of prostatitis. Differences have been reported in the frequency of 3 alleles near the phosphoglycerate kinase gene between patients with CPPS and controls, a gene associated to familiar prostate cancer, hypospadias and specially androgen insensitivity (25).

In patients with CP/CPPS there is a higher serum level of androstenedione and testosterone, with a lower serum level of cortisol. In 10-19\% of patients there are abnormalities in the afferent and efferent autonomic nervous systems associated to neuropathic pain, linked to erectile dysfunction. At least, CP/CPPs is strongly linked with stress, anxiety and maladaptive responses to stressful situation, problems associated with erectile dysfunction. What kind of therapy we could use for sexual dysfunction? Unfortunately, there are still few studies in sexual dysfunction treatment. Alfuzosin $10 \mathrm{mg}$ could be used for chronic prostatitis, improving IPPS score and bother score (26), but this alpha-blocker improved sexual function with lower pain/discomfort and better rigidity and increased ejaculate. Also use of doxazosin shows a reduction of NIH-CPSI (27), but demonstrates a not yet clear role of alpha-blockers for sexual dysfunction in CP/CPPS patients. Trigger point release and paradoxical relaxation training of pelvic floor could also have considered in a multimodal therapy for chronic prostatitis.

This training shows an improvement in pain, urinary and sexual scores after therapy, as assessed by Pelvic Pain Symptom Survey. Phytotherapy represents an attracting option: treatment with curcumin and Calendula extract improved significantly IIEF-5 and PEDT in patients with CP/CPPS type III (28) and quercetin ameliorated erectile dysfunction in streptozotocin-induced diabetic rats (29).

\section{UTILITY OF ULTRASOUND IN PATIENTS WITH PROSTATITIS: COMPUTERIZED ANALYSIS \\ (Matteo Boltri)}

Prostatic ultrasound represents the main imaging test in the work-up of either acute and chronic prostatitis. TRUS and transperineal (TPUS) approaches are superior to transabdominal ultrasound with TRUS being more accurate (30). Transrectal probes are divided into monoplanar, biplanar and end-fire according to transducer arrangement. The US anatomy of apex is well defined by linear probes, whereas end-fire probes better define the base. Color-Doppler mode, tissue harmonic imaging and contrast-enhanced techniques may provide additional information. Utility of ultrasound in the evaluation of acute prostatitis might be of clinical interest in the differential diagnosis of parenchymal abscess (31) or in the detection of a significant post-voiding volume, which is an indication for temporary bladder catheterization. The role of ultrasound in the work-up of chronic bacterial prostatitis (CBP) and chronic pelvic pain syndrome (CP/CPPS) is still debated. To date, no specific hypohyperechoic pattern has been clearly associated with CBP and $\mathrm{CP} / \mathrm{CPPS}$. The detection of hypoechoic periurethral zone volume, posterior prostate lip thickness and bladder neck thickness might be a hallmark of CP/CPPS (32). Hyperechoic areas should be described in the ultrasound report because of their clinical significance. Prostatic calcifications are common in the elderly, although younger people with CBP and CP/CPPS also develop prostatic calcifications of varying size, that could be associated with: presence of a more intense chronic inflammation, positive cultures of the prostatic fluid, longer duration of symptomatology according to NIH/CPSI score (33) and lower efficacy of antibiotic treatment in eradicating the infection of the prostate (34). For a long time the evaluation of the presence of prostate calcification has been based on subjective evaluations, ending in a qualitative dichotomy between patients "with" and "without" calcifications. The development of a standardized method for a quantitative assessment of such calcification has been advocated. Transrectal images of the prostate acquired with a standard protocol can easily been analyzed using a digital-processing software, able to calculate the extension of calcification area. Open-source software like ImageJ by NIH are of great importance in making the access to this technology easier. The relation between the area of prostatic calcification and the prostate area can be expressed as a percentage. In a recent study it has been demonstrated that in a quantitative-based model, a higher percentage of prostatic calcification is more frequently observed in patients with chronic bacterial prostatitis and is related to worse urinary symptoms (35). The utility of an objective method could be of augmented interest either for researchers and clinician. 3D transrectal scanners integrated with a digital-processing software could lead to a better comprehension of the utility of this procedure.

\section{Multiparametric Magnetic Resonance Imaging OF NEOPLASTIC AND NON-NEOPLASTIC LESIONS}

\section{(Pieter J.L. De Visschere)}

Multiparametric Magnetic Resonance Imaging (mpMRI) is the current state-of-the art imaging modality in the 
assessment of patients with suspected or confirmed prostate cancer (PC). It consists of morphological T2weighted images (T2-WI) supplemented with functional imaging techniques such as diffusion-weighted (DWI) imaging, dynamic contrast-enhanced imaging (DCE) and/or MR spectroscopic imaging (MRSI). T2-WI exquisitely depicts the prostatic anatomy and pathology. DWI provides information about the amount of random movement of water molecules as determined by tissue density and cell organization. In DCE, the prostate is repetitively scanned before and during intravenous bolus injection of contrast agent. MRSI demonstrates the relative concentrations of the cellular metabolites citrate and choline in the prostate.

Poorly differentiated PC can be detected on mpMRI with high accuracy as it typically appears as a low signal intensity (dark) lesion on T2-WI, with restricted DWI, strong contrast enhancement on DCE and high choline/citrate ratio on MRSI (36). Currently, there is a trend to treat only patients with clinically significant PC. In patients with elevated PSA, it is advantageous to perform mpMRI of the prostate before a biopsy. When a suspicious lesion is detected on mpMRI, a targeted biopsy can be performed.

When a suspicious lesion is detected on mpMRI, a targeted biopsy can be performed. When mpMRI is normal, it has been shown that a biopsy postponed (provided that the patient is closely followed up), as alternative to systematic biopsies (37), but the debate is still ongoing about which strategy should be recommended (38).

Interpretation of mpMRI may however be difficult, because every prostate exists of a mixture of histological conditions, which are highly variable in extent and distribution among patients and some of them may mimic PC. In our own study (36), we compared a series of whole-mount radical prostatectomy specimens with the corresponding mpMRI images. Pure normal prostate glands are iso-intense on T2-WI and the high signal intensity areas represent cystic atrophy (CyA) or largegland variant of simple atrophy (SA). Due to the high water content of CyA it can easily be recognized on mpMRI and PC can be excluded with high certainty. Inflammation, adenosis, post-atrophic hyperplasia (PAH) and high-grade prostatic intra-epithelial neoplasia (HGPIN) may mimic well differentiated PC on mpMRI because they all show indistinct low signal intensity on T2-WI, moderate contrast enhancement on DCE and slightly decreased citrate concentrations on MRSI (39, 40). On DWI, there is a considerable overlap in imaging characteristics between inflammation and well-differentiated PC (41).

The restricted diffusion in (peri)glandular inflammation may be explained by the high density of inflammatory cells. Granulomatous prostatitis, a chronic inflammation that may develop after Bacillus Calmette-Guerin therapy for bladder cancer, is a well-known mimicker of PC on mpMRI. A variety of benign conditions may thus mimic PC and act as confounding factors in the discrimination between neoplastic and non-neoplastic lesions at mpMRI. It is the challenging role of the radiologist to distinguish this multitude of benign or indolent conditions from aggressive forms of PC.

\section{Causative pathogens of bacterial prostatitis}

(Alessandra Sensini, Christian Leli)

Any microorganism virtually can cause prostatitis. Bacteria infect prostate gland by: ascending the urethra, reflux of urine into the prostatic ducts, direct inoculation of bacteria through inserted biopsy needles or hematogenous seeding. Enterobacteriaceae, especially Escherichia coli, are the predominant pathogens in acute and chronic bacterial prostatitis, but an increasing role of Enterococci has been reported $(42,43)$. Many strains of these uropathogens exhibit the ability to form biofilm, which can be responsible of the treatment failure. Moreover, the emergence of multidrug-resistant organisms, mostly by means of extended-spectrum beta-lactamases, AmpC beta-lactamases and carbapenemases for Enterobacteriaceae, vanA gene for Enterococci and mecA/mecC genes for Staphylococcus aureus, make antimicrobial therapy very challenging. Fungal etiology is generally limited to patients with impaired immunity. Sexually Transmitted Infections (STI) agents, in particular Chlamydia trachomatis, have been also considered as causative pathogens of chronic bacterial prostatitis (44). Due to the improvement of diagnostic technologies, recent studies supported the etiologic role of Mycoplasma genitalium, a cell wall-deficient small bacterium belonging to the Mycoplasmataceae family, as a true causative pathogen of STI and possibly of prostatitis. Under the designation "Genital Mycoplasmas" are included other species, Mycoplasma hominis, Ureaplasma parvum and Ureaplasma urealyticum. They are considered commensals of the lower female genital tract, indeed are frequently recovered from genital samples in asymtomatic subjects. Their effective role in genital diseases of both women and men is still a much debated issue. Likewise, if chronic prostatitis/chronic pelvic pain syndrome is really an infectious disease is still doubtful $(45,46)$.

\section{MICROBIOLOGICAL DIAGNOSIS \\ AND MICROBIOLOGICAL PROTOCOL PROPOSALS}

(Maria Agnese Latino, Alessandra Sensini, Christian Leli)

Microbiological diagnosis is imperative to identify the etiologic agent of prostatitis $(19,20,47-49)$. The midstream specimen of urine (MSU) is the sample of choice to test in acute bacterial prostatitis. In presence of clinical signs suggestive of a blood-stream infection, a blood culture should be taken. The traditional Meares-Stamey 4glass test is recommended for the diagnosis of chronic bacterial prostatitis. The 2-glass test (also called Nickel test) is an acceptable alternative. The analyses of data collected by a questionnaire sent to italian urologists showed that a higher number of seminal fluid cultures than Meares-Stamey test were performed for diagnosis of chronic bacterial prostatitis. Semen culture is not recommended by the European guidelines because of low specificity due to possible contamination by urethral and skin bacteria. Moreover, a diagnostic cut-off in colony count for symptomatic patients has not been determined. Semen culture can be used for diagnosis in addition to Meares-Stamey test as $5^{\text {th }}$ glass and results compared to the other samples. If used alone, it should be 
preceded by a first $10-\mathrm{mL}$ void as urethral specimen. All samples should undergo microscopic examination for the presence of leukocytes, culture for isolation of Gramnegative or Gram-positive bacteria and/or fungi and bacterial count, reporting also small numbers of colonies. In case of positive cultures, antimicrobial susceptibility testing should be performed, according to EUCAST rules. Sexually Transmitted Infections agents should be investigated by molecular methods (test of choice) in both patient and sexual partner.

\section{ANALYSIS OF TOTAL EJACULATE IN THE DIAGNOSTIC EVALUATION OF BACTERIAL PROSTATITIS (Vittorio Magri)}

The possible diagnostic role of the microbiological examination of the seminal fluid is still controversial, due to the possible contamination of the fluid in the urethral passage and the presence of secretions from accessory glands (seminal vesicles, bulbo-urethral glands of Cowper and urethral of Litrrè).

The EAU guidelines (19) exclude the use of semen culture in the diagnosis of chronic prostatitis, although the recommendation strength is weak, and the PERG (20) does not mention this test. On the other hand, in the NIH/NIDKK classification (16), microscopic examination of the seminal fluid in the definition of non-inflammatory CPPS (IIIb) and asymptomatic prostatitis (IV) is envisaged. Furthermore, Stamey himself (1) has argued that semen cultures may be likely reliable for the identification of Gram negative infections and other authors have considered the use of this investigation if associated with a collection of urine VB1 (first voiding) and VB2 (midstream) or when it is not possible to obtain the expressed prostatic secretion (EPS) sample with prostate massage (50, 51). In our experience in 81.7 and $99.9 \%$ of patients with chronic bacterial prostatitis and CP/CPPS respectively it was not possible to obtain an EPS sample and that the examination of the seminal fluid in patients with CBP allowed to demonstrate the presence of Gram negative more frequently than in VB3 or EPS (52).

In a 565 series of samples with positive microbiological tests of seminal fluid and/or Meares-Stamey test samples 284 patients $(52 \%)$ had a positive semen test in the presence of negative Meares-Stamey test, 153 (27.1\%) negative seminal examination and Meares-Stamey positive test and 118 (20.9\%) positive concordance of the two tests.

These data agree with a previous study that showed that the semen examination is positive in $78.6 \%$ of samples of patients with chronic bacterial prostatitis and in no case of CP/CPPS.

This observation confirms what was said by Nickel (53) that observed that the culture of the seminal fluid increased the number of patients classified as category II, even in the absence of precise evidence of the literature and data that demonstrate a clinical improvement after antibiotic treatment of patients with positive culture of seminal fluid. Subsequently, however, some numerically consistent studies $(54,55)$ have confirmed that the examination of the seminal fluid may be a good indicator of prostatic infection when the semen was analyzed together with the 4-glass test and a study showed a positive response after antibiotic treatment of infections diagnosed with semen examination.

Finally, the examination of the seminal fluid allows the identification of atypical sexually transmitted pathogens in high percentages (50\% of cases with Chlamydia infection and $73 \%$ of cases infected with Ureaplama urealyticum and Mycoplasma hominis.

In conclusion, the microbiological examination of the seminal fluid may present a useful integration of the results of the Meares-Stamey test.

\section{ROLE OF BIOFILMS: PATHOGENESIS AND THERAPEUTIC IMPLICATIONS}

\section{(Tommaso Cai)}

Chronic bacterial prostatitis (CBP) is diagnosed by clinical symptoms and microbiological analysis by using biological samples from Meares-Stamey test; treatment with appropriate antibiotics is usually prescribed, in line with the European Association of Urology (EAU) guidelines (42). Several times, fluorquinolones are considered drugs of choice to treat patients with CBP, regardless of a bacterial isolation. Antibiotic treatment usually improves the clinical symptoms, although short-term recurrences are reported frequently (56). It is probably due to the incomplete eradication of the causative pathogens, by phenotypical antibiotic resistance at the site of infection and/or lack of antibiotic penetration into prostate tissue. On the other hand, antimicrobial treatment is most effective in acute infection when bacteria are in the 'planktonic' state, before they form biofilms. The role of biofilm-producing bacteria in development of acute and chronic prostatitis have been recently discussed. Bacteria living in a biofilm usually have significantly different properties compared with free-floating bacteria (planktonic) of the same species, as the dense and protected environment of the film allows them to interact in various ways (57). They benefit in this environment by an increased resistance to antibiotics, as the dense extracellular matrix and the outer layer of cells protect the interior of the community. Moreover, it is well demonstrated that biofilm persisting bacteria, which are usually adherent to tissue surfaces through their own fimbriae and slime, represent the main limitation of antibiotic efficacy and the potential site of short-term infection recurrences. Recently, Bartoletti and Cai demonstrated that biofilm-producing bacteria were commonly found in CBP patients and had a significant negative impact on the clinical response to antibiotic therapy (58). Moreover, they demonstrated that the relief of symptoms seemed to be much more inversely related to the bacterial biofilm production than to apparent negative microbiological tests after treatment. On the other hand, Cai et al. focused their attention on the role of bacterial biofilms in the genesis of prostate calcifications, suggesting a possible role of bacterial biofilm in the genesis of prostate calcifications and in the development of symptoms in chronic prostatitis (59). In this sense the role of prostate calcifications should be reconsidered. Prostate calcifications are not only a sonographic sign of 
previous prostatitis but should be considered a locus for difficult-to-treat bacteria (organized in a biofilm and having the potential to persist after common antibiotic treatments) within the prostate tissue. The presence of a bacterial biofilm represents a chronic inflammatory stimulus that could lead to the development of symptoms related to the grade of inflammation and the immune response of the patients. In the case of high-grade inflammation, the patient could report urinary or pelvic pain. The fluctuating symptomatology reported by the majority of patients might be explained by variation in the inflammatory response to the development and maturation of the bacterial biofilm (59). The antibiotic treatment is probably effective in mitigating the grade of the infection but is not fully effective in eradicating the bacterial biofilm. Future studies should be designed to explore whether effective eradication of the bacterial biofilm could be associated with a good medium- and long-term clinical outcome of treatment.

\section{RESistance OF GERMS TO ANTIBACTERIAL DRUGS IN PATIENTS WITH CHRONIC BACTERIAL PROSTATITIS (CBP): THE HELLENIC EXPERIENCE}

(Konstantinos Stamatiou, Nektaria Rekleiti, Vaia Papadouli)

CBP is a very common and highly bothersome urologic condition. It remains poorly understood $(14,60,61)$. Despite progress in its management, many cases are undertreated and a significant number relapse. The reasons are practically unknown and include host, bacterial and treatment-related factors. Inappropriate treatment, incomplete treatment and increased resistance of responsible bacteria to antibiotics have been proposed to contribute most (62-65). While the two first conditions can be easily rule out, the hypothesis of alteration of drug resistance patterns of responsible bacteria remains relatively unclarified.

We planned a study to retrospectively investigate the resistance of microbes to antibacterials in patients with chronic bacterial prostatitis that had as secondary objective to determine whether the resistance of pathogens increases in patients with CBP recurrence. We studied bacterial isolates from urine and/or prostatic secretions or sperm cultures obtained from individuals with CBP visiting the prostatitis clinic of our department since its establishment (03/2009). Patients underwent the Meares-Stamey test (a few cases underwent the 2-glass test). Depending on medical history and specific symptoms, urethral smear and sperm cultures were additionally obtained from several patients. Those presenting with febrile prostatitis were investigated by a midstream specimen of urine culture (MUC) only. Samples from patients diagnosed with chronic prostatitis for the first time were compared with those of patients with a history of chronic prostatitis and previous antibiotic treatment. The Meares-Stamey test was considered positive when: 1) bacteria grew in the culture of the EPS and VB3/PoPM (post-prostate massage) urine sample but not in VB1 and VB2/PrPM (pre-prostate massage) sample; 2) bacterial colonies in VB3 were higher than that of VB1 and VB2 samples. Given that no standard cut-off level of the number of bacteria in both urine and prostate secretion samples exists for the diagnosis of chronic bacterial prostatitis, we defined no lower acceptable level for either one. Bacterial identification was performed using the Vitek 2 Compact system and susceptibility testing was performed by disc diffusion and/or the Vitek 2 system. Interpretation of susceptibility results was based on Clinical and Laboratory Standards Institute (CLSI) Guidelines. Recorded demographical data and medical history of the patients were revised: patients suffering from conditions affecting either bacterial virulence or host response (eg. immunodeficiencies, abnormalities of the urogenital system) and individuals who received antibiotics or immunosuppressive treatment within 4 weeks from the visit were excluded from the study.

The statistical analysis was performed using Fisher's exact test of significance. The accepted level of significance in this study was 0.05 ( $p$ value $<0.05$ is significant). The locally appointed Ethics Committee approved the research protocol. A total of 548 bacterial isolates obtained from the eligible patients in 1324 visits owing to CBP recorded over a 6-year period (03/2009-05/2015) were analyzed.

In 114 cases the number of colonies was quite similar in both VB2/pre-PPM and VB3/post-PPM cultures. These cases were excluded from the study. In addition 44 cases with negative cultures (despite presence of bacteria in EPS/VB3/post-PPM) were also excluded from the study as possibly false negative since no previous antibiotic intake was reported. The remaining 390 out of 548 bacterial isolates diagnosed as CBP finally consisted the material of the study. Of them, 253 (44 EPS/sperm and 209 VB3/PPM) were from patients diagnosed with CBP for the first time (group A) and 137 (42 mid-stream urine, 51 EPS/sperm and 44 VB3/PPM) were from patients with a history of CBP and previous antibiotic treatment (group B) (Table 1 in Supplementary Materials). The most frequent pathogen -in both groups was E. coli. Other frequent types were Coagulase negative Staphylococci (hominis \& haemolyticus) and Enterococcus spp. The overall frequency of gram (+) was greater than that of gram (-). Of note, bacterial frequencies were similar in both groups (A and B) (Table 2 in Supplementary Materials). Most cases were found with one type of bacteria from each isolate (monomicrobial) however several cases in both groups (49 \& 43) were identified with more than one type of bacteria from each isolate (polymicrobial) (Table 3 in Supplementary Materials).

Regarding clinical relapses, pathogens most commonly associated were Enterococcus faecalis, Staphylococcus CoN and $E$ coli. The mean time interval between chronic prostatitis relapses was 13.9 months (minimum 2 and maximum 56 months). In sperm cultures, in both groups, the most frequent isolate was Enterococcus faecalis (13 and 8 respectively). A remarkably higher Enterococcus faecalis isolate resistance was noticed in group B (69\% vs 25\%) (Table 4 in Supplementary Materials).

In urethral cell/discharge cultures Staphylococcus CoN and Clamydiae trachomatis were the most common pathogens in both groups (Table 4). Generally, a relatively increased resistance to quinolones was observed and a sufficient degree of susceptibility to the least used antibiotics (TMP-SMX, tetracyclines, aminoglycosides, penicillins, and macrolides) (Table 5 in Supplementary 
Materials). In some cases cross resistance between ciprofloxacin and newest quinolones was not observed. The nature of this study explain the high rate $(41.3 \%)$ of positive Meares-Stamey and/or 2-glass tests, however, combined with the fact that no cut-off level of the number of bacteria in both urine and prostate secretion samples was used for the diagnosis of CBP may indicate a relative high underdiagnoses rate. The low number of assessable EPSs in this study may indicate the need of better preparing (e.g. abstain from sexual intercourse for 3 to 5 days before $\mathrm{S} / \mathrm{M}$ test). In confirmation to the above, the number of assessable EPSs in Group B was greater probably because of the familiarization of patients of Group B with the examination process.

The proportion of Gram-positive isolates in the current study is high. The reason explaining the above fact is unknown however it may be associated with the better understanding of the role of Gram-positive bacteria in the development of the disease and the consequent awareness of clinicians and laboratory assistants. The rate of polymicrobial isolates was significantly higher in group B than in group A (31\% vs 19\%). The interpretation of this finding is twofold: on one hand it is possible that repeated antibiotic treatment reveals participating microbial members of prostate biofilm and in the other hand may suggest a chronic decline of the immune system function.

Our finding of increased resistance to quinolones has been previously described. Combined with the finding of sufficient degree of susceptibility to the least used antibiotics this fact can be easily attributed explained by the over-prescription of quinolones in our country. High resistance rates of Enterococci strains may reflect its intrinsic resistance to antibiotics. Of note, differences in susceptibility between Enterococci strains in monomicrobial isolates and polymicrobial isolates may be explained by genomic interactions.

Notably, the coexistent urethral infection found in patients of both groups indicates the continuity of the infection of the genitourinary tract system 4 . In addition, the fact that the findings from sperm cultures were comparable to those of EPS and post PM cultures supports the supplementary role of sperm cultures to the MearesStamey test. Finally, the wide variation in the number of colonies, the presence of different microorganisms in the same culture as well as the presence of CoN Staphylococcus, strengthen the newer appreciation of chronic prostatitis as a biofilm disease.

In conclusion, given the regional variation of the distribution of uropathogens and their susceptibility pattern to antibiotics, knowledge of the susceptibility of causative microorganisms to various antibiotics is necessary in order to select the optimal treatment thus providing better eradication rates and make the creation of drug-resistant strains less likely.

\section{Medical tReatment of CHRONIC Bacterial PROStatitis} (Alberto Trinchieri)

Chronic bacterial prostatitis (CBP) is a clinical entity defined by the isolation of bacteria in the prostatic secretion that according to National Institutes of Health -
National Institute of Diabetes and Digestive and Kidney Diseases (NIH - NIDDKD) criteria is classified as category II. The use of sequential bacteriologic localization cultures represents the most accurate method for diagnosing CBP. The most common organism associated with CBP is Escherichia coli, although infections with Klebsiella, Enterobacter, Proteus, Pseudomonas, and enterococci have also been documented (66). In CBP patients biofilm-producing bacteria were frequently demonstrated as an explanation of the unsatisfactory response to antibiotic therapy (58). Antimicrobials are the first line agents for the treatment of CBP (67). The success of antimicrobial treatment of chronic bacterial prostatitis depends on the antibacterial activity and the pharmacokinetic characteristics of the drug which must reach high concentrations at the site of infection, that is prostate secretion and prostate tissue (68).

\section{Diffusion of antibiotics in prostatic secretion/tissue}

To penetrate the prostatic epithelium, the drug must be lipid soluble, have minimal binding to serum protein and favorable size, shape and degree of ionization in order to diffuse across biological membranes in presence of a $\mathrm{pH}$ gradient (considering that ionized molecules do not cross epithelial membranes). The acid molecules reach greater concentrations in the plasma $(\mathrm{pH} 7.4)$ and the basic ones in the acidic prostatic fluid. Beta-lactam drugs have a low pKa and poor lipid solubility, and thus penetrate poorly into prostatic fluid; macrolides, tetracyclines and trimethoprim are bases showing excellent penetration into prostatic fluid and tissue.

Fluoroquinolones are amphoteric and have a more complex behavior acting either as zwitterions or neutral molecules depending on the medium. Experimental results in the dog confirm this tendency (Table 1 in Supplementary Materials). Experimental animal studies are not easily transferred to the human clinic because the $\mathrm{pH}$ of the prostatic secretion in humans is less acidic and it is increased in chronic prostatitis. Evaluation of tissue concentrations of antimicrobials measured on samples coming from endoscopic prostate resections after antibiotic administration confirms the good penetration of fluoroquinolones in prostatic tissues (Table 2 in Supplementary Materials).

\section{Clinical results of antibiotic treatment in CBP}

Before 2000 there are only few randomized studies on the use of non-quinolone drugs in the treatment of CBP, the studies are underpowered so it is difficult to draw conclusions on the effectiveness of these treatments (Table 3 in Supplementary Materials).

In patients with CBP treated with trimethoprim/sulfamethoxazole (TMP/SMX) cure rates of $0 \%$ to $71 \%$ were reported. When treatment was prolonged for over a 12week period the cure rate was about $40 \%$. Tetracyclines, especially doxycycline and minocycline, and macrolides have been extensively used to treat CBP. In a RCT minocycline demonstrated better microbiological (45 vs $21 \%$ ) and clinical (65 vs 46\%) cure rates than cephalexin. In a small series, use of carbenicillin indanyl sodium has been associated with cure clinical and microbiological rates of 93 and 75\% respectively and a RCT of CBP treatment demonstrated similar cure rates of carbeni- 
cillin and ofloxacin. Amoxicillin-clavulanic acid or clindamycin were used to treat patients with prostatic infection resistant to empirical treatment with quinolones (50\% anaerobic bacteria). In more recent years the antibiotic treatment of CBP was mainly based on the use of fluoroquinolones that, given for 2 to 4 weeks, cured about $70 \%$ of men with CBP due to their broad antibacterial spectrum and efficient distribution to the prostate tissue and glandular ducts (Table 4 in Supplementary Materials). Fluoroquinolones are generally well tolerated but In some patients prolonged use of quinolones may be contraindicated due to potential adverse effects in presence of various contraindications (history of tendonitis or long QT syndrome).

\section{Randomized clinical trials}

The meta-analysis of Perletti et al. took into consideration the RCTs published between 1966 and 2012 (69). Authors concluded that for the treatment of traditional pathogens the different fluoroquinolones used in the treatment of CBP have equal microbiological and clinical efficacy. The rate of adverse events of treatment also appeared to be equivalent. On the contrary, for the treatment of Chlamydial prostatitis macrolides were shown to be more effective than fluoroquinolones, both microbiologically and clinically. No differences were observed in microbiological and clinical efficacy and adverse effect between macrolides and tetracyclines for the treatment of patients with CBP caused by intracellular pathogens, both Chlamidial and Mycoplasma (Table 5 in Supplementary Materials).

\section{Alternative antibiotic regimens}

The increased emergence of bacterial resistance and the decline in newly developed antibiotics are limiting the armamentarium for the treatment of CBP. The possible options to counteract this problem are the increase in the dosage of the antibiotics already in use, the combination of antibiotics and the reintroduction of "old" antibiotics that were previously abandoned or not used for the treatment of CBP (Table 6 in Supplementary Materials). Aminoglycosides diffuse in the prostatic tissue and fluids although less than other antibiotics and in previous years, some aminoglycosides, such as kanamycin and streptomycin were successfully used in small series of patients with CBP. A recent larger study of the administration of aminoglycosides alone or in combination with a $\beta$-lactam antibiotic showed microbiological eradication and clinical remission in $79 \%$ of patients. Genetic testing of patients for mutations predisposing to sensorineural deafness allowed safer administration of aminoglycosides. Orally absorbed fosfomycin trometamol has also been proposed for the treatment of CBP because of its good penetration in prostatic tissue. A recent review found two small series and two case reports of patients with CBP treated with fosfomycin after treatment failure with fluorquinolones and TMP/SMX (70). Fosfomycin was administered orally ( 3 grams every 48 or 72 hours) for periods of 2 to 6 weeks, although in some critical cases it was administered for longer periods of up to 16 weeks. In the two series, microbiological cure rate $>50 \%$ and of clinical cure rate of $50-77 \%$ were reported. The results of these studies suggest that aminoglycosides and fosfomycin could be considered as a therapeutic alternative for the treatment of quinolone resistant CBP although their use should be still validated by randomized-controlled studies. An another option to improve the success rate of antibiotic treatment of CBP is the association of two antibiotics. In particular, macrolides can be associated with quinolones to exploit their ability to reduce biofilms growth. Combination treatment of ciprofloxacin and azithromycin showed a $64.2 \%$ microbiological eradication rate after a 6-week cycle of therapy that reached $83.9 \%$ after a second 6-week cycle in patients showing persistence of infection or reinfection at the end of the first cycle of treatment. Combination treatment showed high eradication rates of infection by both traditional uropathogens and unusual pathogens. An higher dose of ciprofloxacin $(750 \mathrm{mg} /$ daily $)$ in combination with azithromycin (500 mg, thrice-weekly) for 4 weeks showed enhanced eradication rates and lower inflammatory white blood cell counts compared to a 500 $\mathrm{mg}$ /daily dose for 6 weeks.

\section{Locally injected antimicrobial drugs}

Local injection of antibiotics into the prostate has been reported to be effective although no RCT validated this modality of treatment The potential advantage of direct injection into the prostate should be to bypass the prostatic capsule to allows use of antimicrobials that are not easily concentrated in the prostatic tissue after oral administration. Small case series showed encouraging results and a small RCT (50 men with prostatic secretions sensitive to amikacin) demonstrated that anal submucosal injection of amikacin for 10 days significantly improved clinical and bacteriological cure rate at 3 months in comparison with intramuscular injection for the same period.

Adjuvant treatment with herbal products and probiotics A few RCTs on adjuvant treatment with herbal products (mainly Serenoa repens extract) and probiotics have been published (Table 7 in Supplementary Materials) The combination treatment was able to improve the clinical (and in some studies the microbiological efficacy) of prulifloxacin in patients affected by CBP. In patients with CBP and irritable bowel syndrome a prolonged treatment with rifamixin and probiotics was effective in lowering the progression of prostatitis into more complicated forms of male accessory gland infections.

\section{Length of treatment}

The optimal duration of antibiotic treatment for CBP has not been defined by controlled trials, although a study demonstrated the superiority of a 12 week TMP/SMX treatment with respect to a 10 day course of the same antimicrobial agent. However a minimum duration of antibiotic treatment of 4 weeks should be considered. In a RCT clinical success at the 6-month follow up of levofloxacin 750 $\mathrm{mg} /$ day for 2 or 3 weeks was inferior to the standard therapy with levofloxacin $500 \mathrm{mg} /$ day for 4 weeks (71).

Chronic oral antibiotic suppression has been proposed to reduce or eliminate bacterial growth in the urine in order to limit the urinary symptoms of the disease. A chronic suppression approach only mandates adequate 
drug levels in the urine and does not require penetrance of the prostate, thus many antibiotic choices with a safer side effect profile are available, such as nitrofurantoin and cephalosporins. Low-dose trimethoprim (50 or 100 mg once daily), trimethoprim-sulfamethoxazole (40 and $200 \mathrm{mg}$ once daily), and nitrofurantoin (50 or $100 \mathrm{mg}$ once daily) are remarkably effective for this purpose.

\section{BACTERIAL RESISTANCE: WHICH ANTIBIOTICS TO USE? (Valentina Marchese, Alberto Matteelli)}

Enterobacteriaceae are the most common cause of either acute or chronic prostatitis. Resistance to fluoroquinolones, considered the drug of choice for the management of prostatitis, has been increasing since 2000 (72). The progressive increase in fluoroquinolone resistance is also associated with the spread of extended spectrum $\beta$-lactamase (ESBL), which are enzymes that confer resistance to most beta-lactam antibiotics with the exception of carbapenems and, in some selected cases, betalactam/beta-lactamase inhibitors (70). These enzymes are frequently associated with the expression of additional genes harboring resistance to other antimicrobial classes, such as fluoroquinolones and aminoglycosides (73). Treatment of acute and chronic bacterial prostatitis represents always a challenge, as only few antimicrobials reach therapeutic concentrations in the prostate (72). High lipid solubility, a low degree of ionization, a high dissociation constant ( $\mathrm{pKa}$, allowing diffusion of the unionized component into the prostate), low protein binding, and small molecular size enhance molecular penetration within prostate (72). Only a limited number of agents adopted for infections due to multi-drug resistant (MDR) gram-negative bacteria (showing resistance to at least three different classes of antimicrobials) have these characteristics (72). In some cases, even if limited pharmacokinetic data available, they have been described to be effective in treating prostatitis (72). For severely ill patients, empirical coverage for MDR bacteria should be provided in presence of risk factors such as hospitalization, recent use of fluoroquinolones and/or beta-lactams, immunosuppression, recent invasive procedures (73). In all other cases, especially in chronic prostatitis, antimicrobial treatment should be guided by drug susceptibility test (DST). Whenever possible outpatient treatment should be preferred, but the majority of antibiotics for MDR bacteria require parenteral administration. Studies on site-specific pharmacokinetic and pharmacodynamic of piperacillin-tazobactam and meropenem justify their administration in susceptible gram-negative prostatitis $(74,75)$. Prostate tissue penetration of colistin has not been studied and should possibly not be used. Tigecycline undergoes minimal urinary excretion and is usually not considered the first choice for susceptible MDR gram-negative bacteria in urinary tract infections. Nevertheless, few case reports describe the utilization of tigecycline in susceptible strains, with variable clinical and microbiological outcomes (76). So far, Fosfomycin seems the most interesting drug for its susceptibility profile, prostate penetration and availability of oral administration. In patients with bacterial prostatitis caused by antimicrobial-resistant E. coli, oral fosfomycin has shown clinical cure rates of $50-77 \%$ and microbiological eradication rates above $50 \%$ (70). Ceftolozane-tazobactam and ceftazidimeavibactam are two novel drugs which have been introduced for the management of MDR gram-negative infections. At the moment, there are no data on their utilization and penetration in prostate tissues. However, based on previously available data on cephalosporins prostate penetration, both are unlikely to be considered the primary choice in prostate infections, but further studies are needed to assess their possible role in this clinical setting.

\section{Antibiotic-Resistance, A PUblic heAlth PROBLEM}

\section{(G. Maierna)}

The problem of antibiotic resistance poses some questions. 1) When did it become a public health problem? 2) What is the answer of scientific societies to this problem? 3) How civil society deals with antibiotic resistance? In the 40s, shortly after the introduction of the antibiotic into the therapeutic armamentarium of the clinicians, there appeared the first bacterial resistance. From the 60s onwards it has been a progressive and constant increase of antibiotic resistances that has been overcome with the use of new molecules that were periodically synthesized and marketed. In the last decades it is no longer like that. The antibiotic resistance is still increased and many bacterial strains also became multi-resistant to various antibiotics (77-81). This modification of the bacterial ecosystem has been accompanied by progressive abandonment of the research for new anti-infective by most pharmaceutical companies. Meanwhile the ecosystem has further changed and not only for the use and abuse of antibiotic therapy in the human field but also for the spread in the veterinary, zootechnical and aquaculture sectors. All this brought to recent finding of infections related to bacteria that are less sensitive to antibiotics available and always more often multi-resistant, if not even resistant to all the antibiotics tested and available. At this point the diffusion of bacterial resistance has so spread to make the phenomenon no longer a problem limited to some clinical cases to be treated in hospital but a global threat that we have to considered as a public health problem. In this last decade, in particular, it has started a run to find solutions (at least so hopefully). The alternative is a return to the pre-antibiotic era when there were no suitable drugs to treat most infections. Of course, now there are the alarms of the scientific and health world to combat the phenomenon but the reaction of the political authorities and civil society is still ongoing. The G20 of Health, held in Argentina in 2018, like many other international meetings, confirmed the "One Health" plan presented in May 2015 at the $68^{\text {th }}$ World Assembly WHO. Everyone agrees for this global and synergistic action at world and national level promoting a collaborative and inter-sectorial commitment among the various operators of human and veterinary medicine, agriculture and food production and consumers. It is crucial to increase the level of awareness that a prudent and responsible use of antibiotics is necessary in order to counteract antimicrobial resistance that is a growing threat involving 
infections caused by bacteria, fungi, parasites, viruses to determine a progressive a reduction of efficacy of antibacterial, antifungal, antiparasitic and antiviral chemotherapeutic drugs. At this point the treatment of patients with infection becomes difficult, expensive and often impossible. For the most fragile, immunocompromised, and elderly this results in a prolongation of the disease, and in the hospitalization and always more often an increase in mortality. In the "One Health" program of the WHO the objectives to be pursued are: improve awareness of antimicrobial resistance; reinforce knowledge with surveillance and research; reduce the incidence of infections; optimize the use of antimicrobial drugs; develop the necessary investments with adequate financial support. Also in September 2015 the European Parliament approved a resolution for the development of "One Health" in human and animal health to limit multi-resistance to antimicrobials in these areas. At European level, the European Center for Disease Prevention and Control (ECDC), with its own specific prevalence studies conducted among 2011 and 2017 identified as a significant problem of public health related Infections assistance and antimicrobial resistance. Various microorganisms, taken into consideration for their characteristics of pathogenicity, resistance and epidemiology, are considered in these years a real emergency for their ability to resist the action of different antimicrobial agents with various resistance mechanisms. The American Society of Infectious Diseases (IDSA) in 2008 hasgrouped six pathogens in the acronym ESKAPE from the initials of their names: Enterococcus spp, Staphylococcus aureus, Klebsiella pneumoniae, Acinetobacter baumannii, Pseudomonas aeruginosa, Enterobacter spp. The CDC quantified in 2008-2011 an annual number of infections supported by ESKAPE equal to 130,000 cases with 15,000 related deaths. This evaluation proved to be just outdated for the period 2011-2017 when some microbial species, endowed with complex resistances, have shown an increase in their epidemic impact with resistance phenotypes more difficult to treat while other microbial species, not included in the ESKAPE, have become clinically relevant as Streptococcus pneumoniae, Neisseriae gonorrhoeae, Clostridium difficilis and Candida spp. In hospitals, infections caused by antibiotic-resistant bacteria are now associated with greater morbidity and mortality as well as a longer hospitalization, compared to infections by susceptible bacteria. Every year in the world, the antibiotic resistance determines 700,000 deaths of which 25,000 in Europe with a cost of 1.5 billion euros. If the antibiotic resistance will remain at current levels of growth, the deaths could reach 10 million in 2050. For this, according to $\mathrm{WHO}$, antimicrobial resistance is considered one of the biggest threats to public health due to its epidemiological impact. The WHO underlines how the inappropriate use of antibiotics has led to the phenomenon of antibiotic resistance. By using antibiotics in inappropriate doses and timing, treating non bacterial infections with antibiotics, using an intramuscular route when the oral route is appropriate, not following the guidelines of prescription or for inappropriate self-prescription or use of antibiotics beyond the necessary. Some studies have shown that in hospital 30-50\% use of antibiotics used is inappropriate and that improving prescription determines a reduction of antibiotic resistance and related hospital infections assistance. The final consequence of antibiotic resistance is the reduction of effectiveness of antimicrobial therapies puts at risk the anti-infective medical therapy that currently allows us to treat prosthetic infections, infections in severe oncological-haematological diseases and organ transplants and more. If the current prescribing behaviors and inappropriate use of antibiotics will not be changed, in 2050 the antibiotic resistance will cause more deaths from infection than cancer. Hence the commitment to antibiotic government programs (antimicrobial stewardship) in order to improve: the prescription, with the use of optimal therapy regimens, diagnosis, surveillance and prevention of bacterial infections. All this with strategies of control of infections and their transmission in acute and long-term facilities; antimicrobial stewardship programs for antiinfective drugs; re-evaluation of the therapeutic potential of previous used anti-infective drugs; improvement of microbiological response times to reduce the duration of empirical therapy; development of new antimicrobial molecules. The American Society of Infectious Diseases (IDSA), in its guidelines, highlights how the Antimicrobial stewardship (AS) has a fundamental role in achieving prescriptive and responsible appropriateness, not only for the individual patient but for the whole general context of the ecosystem. Moreover the activity of the Infectious diseases department in the hospital and on the territory can help to sensitize the clinicians to follow the principles for the correct use of antibiotics with appropriate use that requires an adequate microbiological study before the prescription; prescription of the drug in the presence of infection and not colonization; correct administration by dose, time and duration in respect of pharmacokinetics and pharmacodynamics of the molecule (PK/PD); de-escalation of therapy based on microbiological tests and clinical parameters; optimal surgical prophylaxis by choice, time of administration and duration (82).

\section{Management of Chronic Prostatitis/Chronic Pelvic Pain Syndrome}

(Florian ME Wagenlehner)

CP/CPPS is a not well defined entity. In everyday clinical practice frequently the diagnosis is based upon pain symptoms in the abdomen or pelvis region radiating to adjacent areas and might be accompanied with lower urinary tract symptoms. Painful prostate on palpation is also frequently described without any standardization of the investigation. Usually rudimentary diagnosis is done, if at all including a urinalysis and possibly a urine culture. No further refined diagnosis is made and almost always prolonged and multiple antibiotics courses are prescribed, sometimes alpha blockers, or pain medication is added. The difficulties in the management of CP/CPPS arise from the fact that it is a multifactorial condition, with diverse etiologies. So very different circumstances might lead to the same clinical picture, but possibly warrant different diagnosis and treatment. There is no objective diagnosis, such as a histology, that can proof the condition. There is no biomarker that can be used for diagnosis or follow up of patients, and there is lack of novel treatment strategies taking into account pathophysiological pathways. 
In terms of diagnosis there is an agreement that infection should be ruled out by localization tests, as described early by Stamey (1). To what extent ejaculate investigations could be beneficial is not entirely clear. Ejaculate testing is frequently performed on routine examinations heading for mere culture, which frequently provides contamination samples, or in other words reflects the microbiome of the external genitalia. However "next generation" investigations, such as cytokine analysis, cytological typing of immune cells etc., that could help stratifying the immune response can nowadays be performed in clinical routine (83). Epigenetic changes are frequently seen in chronic inflammatory diseases and should be investigated according to systemic and compartmentspecific signals for epigenetic dysregulation of inflammatory factors. By doing so a significant association with systemic and local epigenetic inactivation of a mast-cell recruiting molecule CXCR4, the receptor for CXCL12 was identified (83). The search for biomarkers should include various pathways, including hormonal pathways (84). In one study elevated local estrogen levels associated with an epigenetic down-regulation of the estrogen receptors was identified. Investigating estrogen levels in semen could therefore serve as a promising biomarker to select patients for estrogen targeted therapy (84).

As pain is the main driver of reduced quality of life in patients suffering from CP/CPPS (85), novel therapeutic substances for the treatment of pain would be therefore be highly interesting to test. Anandamide is a cannabinoid (CB) produced on demand in response to elevated intracellular calcium levels in post-synapse. It is an endogenous agonist of the $\mathrm{CBl}$ receptor which exerts potent inhibitory effects on pre-synaptic glutamate release. The fatty acid amide hydrolase (FAAH) is involved in the enzymatic regulation of anandamide and the inhibition of FAAH elevates levels of anandamide in hyperexcited synapse and potentially could reduce pain perception. In a phase 2 study a peripherally active FAAH inhibitor ASP3652 was investigated in CP/CPPS patients, as inhibition of FAAH is hypothesized to reduce the excitability of urinary tract afferents including nociceptors (86). The results of the study however did not show efficacy of ASP 3652 on pain symptoms in patients with CP/CPPS (86). Most monotherapy studies in general have not been successful, since CP/CPPS is a multifactorial disease with different pathophysiological causes. A phenotyping approach, the UPOINT concept, has therefore been recommended (6). This concept includes a multimodal therapy for CP/CPPS in phenotyped patients, where each identified phenotype according to the enlarged UPOINTS classification is treated separately (87). Using such a treatment concept, a clinically appreciable reduction of $\geq 6$ points of the total NIH-CPSI score was achieved in $77.5 \%$ of patients subjected to combination therapy for a period of 6 months (87).

\section{ROLE OF MULTIMODAL THERAPY FOR TREATMENT OF CHRONIC PROSTATITIS}

(Giorgio I. Russo, Gaetano Larganà)

Prostatitis is considered the "black sheep" of the prostate family of disease, due to difficult to understand its causes and its definitive therapy. It can be considered one of the challenges that urologists have to face. In the last decade, in fact, Google trend showed how the term "prostatitis" has been looking several times more compared to the past, like prostatitis and therapy, like prostatitis + phytotherapy and Serenoa repens. What kind of therapy urologists could use against prostatitis? First of all, in case of diagnosis of prostatitis, antibiotics are the firstline agents for the treatment of $\mathrm{CP}$, for 4-6 weeks. Penicillin, fluoroquinolone, third-generation cephalosporin, macrolides could be used for CP/CPPS. If patient has voiding low urinary tract symptoms (LUTS), alphablockers for 4-6 weeks are also used. The use of alphablockers demonstrates an average NIH-CPSI total score reduction, an average pain e average voiding symptoms reduction with an increase of quality of life (88). If pain is present, simple analgesics +/- non steroidal anti-inflammatory drugs (NSAIDs) can be used. Different studies compare the use of rofecoxib and celecoxib against placebo. They demonstrate a pain reduction and a better quality of life (89). Unfortunately, long-term use of antiinflammatory agents for CP/CPPS is limited by complications due to side effect profile, moderate effect on symptoms (predominantly pain) and lack of data for their use. Improvement of results has instead been reached by the contemporary use of alpha-blockers, antibiotics and anti-inflammatory (90), showing a better control of prostatitis symptoms than use of a single drug. In fact, unfortunately, no efficient monotherapeutic option is available. The best evidence-based management of CP/CPPS is a multimodal therapeutic approach addressing the individual clinical phenotypic profile (91); antibiotics, alpha-blockers and anti-inflammatory, although they have an effect on the disease, cannot be recommended as first-line monotherapy but could be considered in a multimodal therapeutic regimen.

A different and new point of view in the treatment of $\mathrm{CP} / \mathrm{CPPS}$ is to considered phytotherapy. It could be recommended as primary therapy or in association with other drugs to treat $\mathrm{CP}$, because of their few side effects. The use of quercetin (500 mg twice a day), in man with Chronic pelvic pain syndrome, show a better control urinary symptoms, a lower symptoms duration and a better quality of life against placebo (92). Cernilton, a pollen extract, show a better control of pain and a 25\% decrease in NIH-CPSI score, with better quality of life against placebo, in CP/CPPS patients (93). Pollen extract was studied against placebo also in association with vitamins (Deprox 500) for pain relief: after only 1 month from start of therapy it was observed a decrease of NIH-CPSI score, although IPSS remain constant. Most important was the comparison between Deprox $500 \mathrm{mg}$ and Ibuprofen $600 \mathrm{mg}$ for early pain relief. Pollen extract demonstrated a better quality of life and a major decrease in NIH-CPSI score, avoiding all the side effect of the continuous use of NSAIDs like ibuprofen. Eviprostat has an identical effect compared to pollen extract in patients with CP/CPPS. IPSS total score, IPSS storage score, IPSS voiding score after 4 and 8 week of treatment with Cernilton or Eviprostat showed no statically difference in results from baseline. Another studied phytotherapy drug is Serenoa repens. Profluss, an associa- 
tion of Serenoa repens plus selenium and lycopene has better results in IPSS score, Qmax score than Serenoa repens alone. In the last years other drug associations were studied for the treatment of patients with chronic prostatitis. An Italian study reported about the association between curcumin and Calendula (Riflog) versus placebo. The results were encouraging, with a reduction of the NIHCPSI score and changes of peak flow, IIEF-5, VAS and PEDT. Moreover, as already mentioned before, multimodal therapy has greater effectiveness than a single therapy. Riflog, in association with alpha-blocker and antibiotics, improves quality of life, $\mathrm{Q}_{\max }$ and reduced Santorini ectasia and number of Stamey positive patients. At last Calendula officinalis could be another phytotherapy drug used in prostatitis, exploiting the numerous effect already studied and know, like antiflammatory, antioxidant, antiedematous or analgesic effects.

\section{Prostatitis and InTestinal diseases}

\section{(Clara Maria Granatieri)}

The association of CP/CPPS syndrome with intestinal symptoms has been described in the literature. In our experience out of 232 patients suffering from prostatic inflammation, 146 (63.2\%) frequently exhibited alterations of intestinal function (alternating constipation and diarrhea, abdominal pain and bloating) and previous urinary infections. The study of functional bowel pathologies (Irritable bowel syndrome - IBS, IDP) has focused the attention on the intestinal microbiota. The interaction of bacterial intestinal flora interaction with food is the basis of many phenomena that influence the state of health or illness. In fact the microbiota, according to its composition and by means of the products of bacterial metabolism, influences the metabolic, immune and inflammatory response of the organism (94). An anti-inflammatory action occurs at the level of Toll-like receptors (TLR); probiotics are able to regulate the balance if intestinal flora, so the TLR can correctly distinguish dangerous antigens from those that must be tolerated. Reduced intake of fiber in the diet alters the intestinal microbiota, with reduced bacterial production of compounds modulating the immune response. To regulate the intestinal flora, proper nutrition is therefore crucial. Numerous studies attest the important role of diet in proper formation and maintenance of the intestinal microbiome. Epidemiological studies have correlated the increase of inflammatory pathologies with "modern" nutrition, the so called "Western diet" that is the intake of large quantities of red meat, simple carbohydrates, fat, refined cereals and poor portions of vegetables, fruit and fish. The damages caused by this diet are due to the inability of the human genome to adapt to rapid changes in the environment, especially diet (95).

The "Mediterranean diet" is more similar to that of our ancestors and is considered the standard diet for human health (96). The complex cumulative nutritional effects of the foods rather than the intake of single macronutrients (proteins, carbohydrates, fats) and micronutrients (minerals and vitamins) play an important role in the protective effect of the Mediterranean diet (96).

The diet has its effects on inflammation both by direct action on the cells and regulation of the composition of intestinal flora. Foods directly influence the immune response and therefore inflammation of intestinal and extra-intestinal tissue. Intestinal cells, in particular enterocytes and immunocompetent cells, are equipped with complex systems for "sensing" foods and respond to them (97). In fact, intestinal cells express pattern recognition receptors, such as the TLR, the NOD-like receptors (NLR) and the Leucine rich alpha-2-glycoprotein1 (LRG1). They recognize both pathogen associated molecular patterns (PAMPs) and damage associated molecular patterns (DAMPs). In fact an inflammation in the absence of pathogens can occur in all the tissues, in response to a wide range of stimuli, which cause stress and damage to cells (sterile inflammation) (98). In the sterile inflammation some nutrients are able to cause conditions of cellular stress. Various DAMPs are released from damaged cells and activate immune cell receptors (TLR, NLR, LRG1) which were originally identified as PAMPs sensors. In particular DAMPs lead to the assembly of a cytosol protein complex, called inflammasome, which activates the caspase- 1 protease with consequent activation and secretion of IL-1beta. The nutrients can therefore interact with the intestinal epithelium and the cells of the system immune, as do viruses, bacteria and other environmental factors, activating the same pathways of cellular signals that activate or reduce inflammation.

\section{MICROBIOTA-EUBIOSIS-DYSBIOSIS}

(Roberto Colombo)

The pool of bacteria and other microorganisms (viruses and prokaryotes) that lives in coexistence in the human intestine is called intestinal microbiota (99-107).

The Microbiota is made up of 100 trillion bacteria in a balanced composition of several divisions (Phyla), genera and bacterial species, which can act as

- "commensals" that do not provide any benefits or harm to the guest

- "symbionts" mainly Bifidobacteria and Lattobacilli with probiotic activity

- "pathobionts" resident bacteria with potential for pathological induction.

The composition and concentration of bacterial genera and species differs in the various segments of the gastrointestinal tract from 102 in the stomach to 1012 in the colon.

The intestinal microbiota implements 3 probiotic functions:

- protective function against pathogenic bacteria from the outside and pathobiont bacteria: this action is carried out by anti-bacterial activity (bacteriocins) for space and nutrient competition and for slight acidification of the environment to inhibit the growth of pathogenic bacteria

- metabolic function by synthesis of vitamins, decomposition of bile acids and above all production of short-chain, butyric, propionic and acetic fatty acids (butyrate is the trophic factor for intestinal mucosal cells) 
- probiotic bacteria, especially Bifidobacteria and Lattobacilli, that also have the function of modulation of the intestinal immune system (GALT: Gut Associated Lymphoid Tissue, $60 \%$ of the entire intestinal system); this occurs because the products of probiotic bacteria (lipopolysaccharides, peptidoglycans) stimulate specific receptors of the dendritic cells of the intestinal mucosa which, for this stimulation, produce Interleukin 10 which stimulates the regulatory T lymphocytes that implement the modulation of the GALT.

In addition, the intestinal epithelial cells produce a mucous layer that covers the intestinal surface, consisting of mucin polymers that act as nutrients and sites of adhesion of probiotic bacteria.

The balanced microbiota is in a state of "eubiosis" with welfare functions for the whole organism. The qualitative and quantitative alteration of the Microbiota is called "dysbiosis" which, by altering the probiotic functions, causes invasive intestinal diseases and correlates with numerous systemic diseases. The causes of dysbiosis in adults are determined by drugs, stress, wrong diet, bad lifestyle, infections and food intolerances.

Dysbiosis can be "deficienct" when caused by drugs or stress or wrong fiber-free diet, or "stagnant" or "putrefactive" when foods such as fats and red meat that stimulate the flora to putrefactive activity prevail in the diet or, on the other side, when fermentable foods (legumes, citrus fruits, etc.) are excessive.

A diagnostic innovation regards the evaluation of the dysbiotic action of colina (by excess of eggs) and carnitine (by excess of red meat). The dysbiotic flora induced by excess intake of these substances produces Trimethylamine Oxide (TMAO). This product stimulates the formation of foam cells, inflammatory cells with oxidized LDL, which stimulate the formation of atheromatous plaque. TMAO represents an important new cardiovascular risk marker.

The presence of dysbiosis mainly determines low-grade inflammation with hyperstimulation of the immune system and endotoxaemia, because the dysbiotic bacteria produce substances that stimulate the receptors of dendritic cells inducing the production of inflammatory interleukins with increased reactivity of T17 and T1 lymphocytes to pro-inflammatory action.

Dysbiosis, as well as other stimuli, such as gluten, determine the secretion by intestinal cells of the zonulin protein, which acts on the "tight junctions" of the intestinal epithelial cells, causing increased intestinal permeability. Dysbiosis, zonulin and consequent low-grade inflammation are the pathophysiological causes of the numerous diseases related to the alteration of the microbiota. The gastrointestinal pathologies are at first local (as leaky gut syndrome) developing food intolerances, subsequently they can worsen when there is a concomitant alteration of the balance of the brain intestinal axis (psychosocial hypersensitivity/excess of catecholamines) with IBS or vice versa when polymorphisms predisposing to inflammation cause the onset of a chronic inflammatory bowel diseases (IBD). Dysbiosis can cause, for the pathophysiological factors mentioned above, systemic diseases such as diabetes mellitus (as the produced inflammatory factors as inter- leuchin-6, IL6, and Tumor Necrosis factor, TNF) determine insulin resistance) or cardiopathies (due to production of Trimethylamine Oxidize, TMAO) or allergies in atopic subjects or autoimmune diseases secondary to synovial migration of inflammatory cells or depression due to reduction of serotonin production by intestinal cells or cystitis and vulvovaginitis in the female caused by migration of pathobionts bacteria of the dysbiotic intestinal flora. The alteration of the microbiota is also related to obesity because of the alteration of the relationship between Bacteroidetes and Firmicutes that are the two main bacterial divisions that make up $90 \%$ of the intestinal microbiota whose relationship represents a main biodiversity index. This ratio is normally about 0.8 , but in obesity it is changed with an increase of Firmicutes that determines an increase in the ability to recover energy from the diet due to increased carbohydrate metabolism.

Low-grade inflammation, increased intestinal permeability, presence of pathobionts bacteria and trans-parietal migration may also be involved in the pathogenesis of acute and chronic prostatitis. Repeated antibiotic therapies that often accompany the clinical process of urogenital and prostatic infections represent a factor that repeatedly feeds the dysbiosis related to these diseases highlighting the importance of the therapy with probiotic bacteria to restore the eubiosis and stop the vicious circle of dysbiosis-urogenital infections. Bacterial therapy is based on the use of live probiotic bacteria, with correct taxonomic identity according to Qualified Presumption of Safety (QPS) and International Depository Authority (IDA) status. The timing of administration of bacterial therapy should never be less than 21 days and the amount of live bacteria should never be less than one billion daily.

\section{HYDROCOLONTHERAPY: THERAPEUTIC OPTION IN PATIENTS WITH CHRONIC PROSTATITIS AND DYSBIOSIS?} (R. Giuberti)

The investigation on the intestinal microbiota in the CP/CPPS has detected less alpha diversity of the microbiota respect to controls (lower presence of Prevotella genus, to which an anti-inflammatory role is recognized) (108).

The microbiota can generate, amplify and maintain a systemic or a local inflammatory condition, causing, as a consequence, a possible painful state, that could have a role in the etiology of the CP/CPPS (109).

Dysbiosis with persistence of pathogenic noxae can activate mast cells causing chronic inflammation. Bacteria belonging to the phylum Proteobacteria have an outer membrane composed mainly of lipopolysaccharides (LPS) that stimulate monocyte activity through various steps. LPS are anchored to the external membrane of the bacteria and are released once bacteria die provoking a reaction from the organism with possible increase of the vascular permeability and consequent inflammatory state. They increase intestinal permeability through an intracellular mechanism that involves the up-regulation of TLR-4, which depends on the membrane expression of CD-14 (110). TLRs are receptors expressed on the membrane of sentinel cells such as macrophages, dendritic cells and antigen-presenting cells (APC). In particular, 
TLR-4 is crucial in the recognition of LPS. The activation of TLRs in the intestinal microbiota by the presence of pathogenic microorganisms induces the triggering of the mechanisms of innate immunity and the onset of inflammatory phenomena. The condition of dysbiosis leads to an indirect dysfunction, therefore not primary but secondary, of the intestinal epithelia barrier which creates a way of entry into the organism, through the blood, of bacteria, giving rise to phenomena of bacterial translocation (bacteria in places other than those of origin). The alteration of intestinal permeability, due to lactobacilli and bifidobacteria deficiency, leads to loss of integrity of the mucosal barrier, passage of antigens in the submucosa and immune activation. The activation of the mast cells maintain an up-regulation with acute and chronic pro inflammatory consequences.

Recent studies have widely established that mast cells can also respond to non-IgE dependent stimulation. In these cases, mast cells appear to undergo ultrastructural alterations of the granular nucleus, that appears dense with electrons, without the classic evidence of degranulation that is related to an increase of IgE. A condition of chronic mild inflammation is developed that reverberates at the intestinal, prostatic and vaginal level.

The best known triggers of this alternative activation path include bacterial toxins, neurotransmitters and stress that may be involved in the pathophysiology of IBS. Patients with IBS have a 150\% increase in mast cells compared to a control group.

The involvement of mast cells in abdominal pain of patients with IBS has been widely demonstrated, in particular the presence of activated mast cells near the nerve endings, is related to the intensity and frequency of abdominal pain. Mast cells represent the most active sentinels towards the external environment having a high quantity of receptors that can be activated by allergens such as food, drugs, cytokines.

The mast cell can acts both by paracrine signaling, especially for the presence of pseudopods which can extend the inflammatory response to blood vessels and nerve endings, and autocrine signaling to itself because it has receptors to the substances that it releases.

Consequently, if the causes of its activation are not removed, the inflammatory process can become chronic. Some studies have shown that dysbiosis can cause the release of zonulin which leads to the passage of endoluminal contents through the epithelial barrier with consequent release of pro-inflammatory cytokines.

Zonulin is a protein that regulates the junctions of the intestinal walls and if in excess, loosens them, favoring a state of intestinal permeability. It was first described in 2000 by Fasano et al. at the Celiac Research Center of the University of Maryland School of Medicine. who focused on the role of zonulin in intestinal tissues during the acute phase of coeliac disease (111).

The values of zonulin may represent the reference parameter for the evaluation of the extent of the intestinal mucosa alteration and the consequent state of its permeability. The values found are significant of the progression of the inflammatory condition and correlated with clinical symptoms and can be a guide of the treatment.

In $22-31 \%$ of patients with chronic bacterial prostatitis and chronic pelvic pain syndrome a condition of IBS can increase the severity of the pain symptom in the following regions: perineum, supra-pubic region, testes, penis, pelvis, inguinal region, rectum, pain in urination, pain during ejaculation and neuropathic pain (1).

Accordingly, the therapeutic approach could aim at restoring the intestinal microbiota through the examination of the stool, the rebalancement of the microbiota, an adequate diet and the application of hydrocolon therapy to eliminate bacterial over-growth and pro-inflammatory toxins generated by lipopolysaccharides (LPS)

The application of hydrocolon therapy in chronic prostatitis is based on the ability of a gentle and targeted flow of water entering the intestine during the treatment sessions to regenerate the intestinal environment, through the elimination of inflammatory components that reside in the microbiota. The regularity of the incoming flow through the targeted maneuvers of the operator, which operates on the water flow and pressure parameters in an appropriate manner, allows to create an environment favorable to the regrowth of a microbiota rich in lactobacilli and bifidobacteria that is essential to maintain the intestinal mucosal integrity and to guarantee an effective motor peristalsis.

The application of hydrocolon therapy in vulvodinia has achieved a significant improvement of pain with concomitant decrease of inflammatory parameters. It is desirable that the application of the technique on subjects with CP/CPPS can lead to an equally significant benefit, in association with therapies targeted to the restoration of a balanced intestinal microbiota and functional to the elimination of the noxae pathogenic of the inflammatory activation that can support the syndrome. The restoration of intestinal eubiosis, through the targeted integration of probiotics, guided by the examination of stools, a healthy and balanced dietary approach aimed at maintaining a balanced microbiota and hydrocolontherapy sessions can represent a new integrated therapeutic approach, centered on the multi-factorial biological etiology, that support a chronic inflammatory process as the CP/CPPS could be defined.

\section{Gynecological investigation of the PaRtNeRs OF CHRONIC BACTERIAL PROSTATITIS PATIENTS}

(Elisabetta Massa)

The human vagina is the location of an ecosystem whom different participants (local microbial populations, local environment and host's characteristics) always are in a dynamic equilibrium. This ecosystem is open to contaminations both from the external and from the intestinal environment, so it is susceptible to colonization from microorganism that can be symbiotic or pathogenic according to their bacterial counts and to their ability to modify the vaginal homeostatic mechanisms. All the participants to vaginal ecosystem (vaginal epithelium, $\mathrm{pH}$, glycogen and lactobacillary flora) are modified along the different ages of a woman due to different hormonal production. A high oestrogen production, such as during puberty or pregnan$\mathrm{cy}$, stimulates the vaginal cells to proliferation and the glycogen storage. Moreover, glycogen facilitates the lactic 
acid production and the lowering of vaginal $\mathrm{pH}$. Moreover, the lactobacillary flora, divided in five groups following the predominant species (L. crispatus, L. gasseri, L. iners, mixed group e L. Jensenii) (112), has a protective role because it stops the pathogens' growth and their cohesion (113). All these mechanisms are the first line in vagina's defences. Furthermore, menstrual cycles, sexual activity, antibiotics or oral contraceptives assumption can modify the vaginal macrobiotic. The vaginal microbiota has an active role in the mechanisms of conception, pregnancy and delivery (time and modality) (114). In presence of disruption of vaginal homeostasis (due to alteration of control mechanisms or to different susceptibility of the host), there are vaginal infections (vaginitis) due to attack from external pathogens or dysbiosis (vaginosis) due to a quantitative redistribution of local flora. For a correct diagnosis, it is important to evaluate the patient's clinical history, characteristic signs or symptoms, vaginal $\mathrm{pH}$ value, the fish's odor test, the microscopic exam with or without staining and a cultural/molecular test. Partners of 399 patients suffering from Chronic Prostatitis or Chronic Pelvis Pain Syndrome: who underwent to a vaginal, cervical or urethral swab showed the same pathogen isolated in male patients, namely Enterobacteria, Uraplasma uralyticum, Gardnerella vaginalis and Chlamydia. Moreover, clinical characteristics of vaginal infections, their association with sexual transmitted diseases (STD), the gynaecological and reproductive consequences and the obstetric complications have to be analysed (115-117).

\section{ACKNOWLEDGEMENT}

To Konpharma Srl for supporting the meeting Prostatitis: A Multidisciplinary Approach (Issues and Controversies), Milano, Italy, 26-27 Oct 2018.

\section{References}

1. Stamey TA. Prostatitis. J Royal Soc Med. 1981; 74:22-40.

2. Young HH, Geraghty JT, Stevens AR. Johns Hopkins Hospital Reports. 1906; 13:272-34.

3. Nickel JC, Nyberg LM, Hennenfent M. Research guidelines for chronic prostatitis: consensus report from the first National Institutes of Health International Prostatitis Collaborative Network. Urology. 1999; 54:229-233.

4. Naber KG, Madsen PO. Antibiotics: basic concepts. In: Nickel JC (ed). Textbook of Prostatitis. Isis Medical Media, Cambridge, UK, 1999: pp 83-94.

5. Litwin MS, McNaughton-Collins M, Fowler FJ Jr, et al. The National Institutes of Health chronic prostatitis symptom index: development and validation of a new outcome measure. Chronic Prostatitis Collaborative Research Network. J Urol. 1999; 162:369-75.

6. Shoskes DA, Nickel JC, Rackley RR, Pontari MA. Clinical phenotyping in chronic prostatitis/chronic pelvic pain syndrome and interstitial cystitis: a management strategy for urologic chronic pelvic pain syndromes. Prostate Cancer Prostatic Dis. 2009; 12:177-8.

7. Cordaro M, Impellizzeri D, Siracusa $R$, et al. Effects of comicronized composite containing palmitoylethanolamide and polydatin in an experimental model of benign prostatic hyperplasia. Toxicol Appl Pharmacol. 2017; 329:231-240.
8. Jiang J, Li J, Yunxia Z, et al. The role of prostatitis in prostate cancer: meta-analysis. PLoS One 2013; 8:e85179.

9. Nair-Shalliker V, Yap S, Nunez C, et al. Adult body size, sexual history and adolescent sexual development, may predict risk of developing prostate cancer: Results from the New South Wales Lifestyle and Evaluation of Risk Study (CLEAR). Int J Cancer. 2017; 140:565-574.

10. Rybicki BA, Kryvenko ON, Wang Y, et al. Racial differences in the relationship between clinical prostatitis, presence of inflammation in benign prostate and subsequent risk of prostate cancer. Prostate Cancer Prostatic Dis. 2016; 19:145-50.

11. Boehm K, Valdivieso R, Meskawi M, et al. Prostatitis, other genitourinary infections and prostate cancer: results from a populationbased case-control study. World J Urol. 2016; 34:425-30.

12. Perletti G, Monti E, Magri V, et al. The association between prostatitis and prostate cancer. Systematic review and meta-analysis. Arch Ital Urol Androl. 2017; 89:259-265.

13. Ding H, Fan S, Zhang L, et al. Does prostatitis increase the risk of prostate cancer? A meta-analysis. Int J Clin Exp Med. 2017; 10:47984808.

14. Krieger JN, Lee SW, Jeon J, et al. Epidemiology of prostatitis Int J Antimicrob Agents 2008; 31 (Suppl 1):585-90.

15. Krieger JN, Nyberg LJ, Nickel JC. NIH consensus definition and classification of prostatitis. JAMA. 1999; 282:236-7.

16. Meares EM, Stamey TA. Bacteriologic localization patterns in bacterial prostatitis and urethritis. Invest Urol. 1968; 5:492-518.

17. Nickel JC, Shoskes D, Wang Y, et al. How does the pre-massage and post-massage 2-glass test compare to the Meares-Stamey 4-glass test in men with chronic prostatitis/chronic pelvic pain syndrome? J Urol. 2006; 176:119-24.

18. Shoskes DA, Nickel JC, Dolinga R, Prots D. Clinical phenotyping of patients with chronic prostatitis/chronic pelvic pain syndrome and correlation with symptom severity. Urology. 2009; 73:538-42.

19. Bonkat G, Pickard R, Bartoletti R, et al. EAU Guidelines Urological infections Edn presented at the EAU Annual Congress Copenhagen 2018, EAU Guidelines Office, Arnhem, The Netherlands.

20. Rees J, Abrahams M, Doble A, Cooper A. Prostatitis Expert Reference Group (PERG). Diagnosis and treatment of chronic bacterial prostatitis and chronic prostatitis/chronic pelvic pain syndrome: a consensus guideline. BJU Int. 2015; 116:509-25.

21. Magri V, Wagenlehner F, Perletti G, et al. Use of the UPOINT chronic prostatitis/chronic pelvic pain syndrome classification in European patient cohorts: sexual function domain improves correlations. J Urol. 2010; 184:2339-45.

22. Magri V, Perletti G, Montanari E, et al. Chronic prostatitis and erectile dysfunction: results from a cross-sectional study. Arch Ital Urol Androl. 2008; 80:172-5.

23. Trinchieri A, Magri V, Cariani L, et al. Prevalence of sexual dysfunction in men with chronic prostatitis/chronic pelvic pain syndrome. Arch Ital Urol Androl. 2007; 79:67-70.

24. Cai T, Pisano F, Magri V, et al. Chlamydia trachomatis infection is related to premature ejaculation in chronic prostatitis patients: results from a cross-sectional study. J Sex Med. 2014; 11:3085-92.

25. Riley DE, Krieger JN. X Chromosomal short tandem repeat polymorphisms near the phosphoglycerate kinase gene in men with chronic prostatitis. Biochim Biophys Acta. 2002; 1586:99-107.

26. Nickel JC, Elhilali M, Emberton M, Vallancien G; Alf-One Study Group. The beneficial effect of alfuzosin $10 \mathrm{mg}$ once daily in 'real-life' 
practice on lower urinary tract symptoms (LUTS), quality of life and sexual dysfunction in men with LUTS and painful ejaculation. BJU Int. 2006; 97:1242-6.

27. Faydaci G, Kuyumcuoglu U, Eryildirim B, et al. Effectiveness of doxazosin on erectile dysfunction in patients with lower urinary tract symptoms. Int Urol Nephrol. 2011; 43:619-24.

28. Morgia G, Russo GI, Urzi D, et al. A phase II, randomized, singleblinded, placebo-controlled clinical trial on the efficacy of Curcumina and Calendula suppositories for the treatment of patients with chronic prostatitis/chronic pelvic pain syndrome type III. Arch Ital Urol Androl. 2017; 89:110-113.

29. Zhang W, Wang Y, Yang Z, et al. Antioxidant treatment with quercetin ameliorates erectile dysfunction in streptozotocin-induced diabetic rats. J Biosci Bioeng. 2011; 112:215-8.

30. Terris MK, Hammerer PG, Nickas ME. Comparison of ultrasound imaging in patients undergoing transperineal and transrectal prostate ultrasound. Urology. 1998; 52:1070-2.

31. Roy C. Imagerie de la prostate. 2005, Elsevier Masson, Paris.

32. Dellabella M, Milanese G, Muzzonigro G. Correlation between ultrasound alterations of the preprostatic sphincter and symptoms in patients with chronic prostatitis-chronic pelvic pain syndrome. J Urol. 2006; 176:112-8

33. Shoskes DA, Lee CT, Murphy D, et al. Incidence and significance of prostatic stones in men with chronic prostatitis/chronic pelvic pain syndrome. Urology 2007; 70:235-238.

34. Zhao WP, Li YT, Chen J, et al. Prostatic calculi in-fluence the antimicrobial efficacy in men with chronic bacterial prostatitis. Asian J Androl. 2012; 14:715-719.

35. Boltri M, Magri V, Montanari E, et al. Computer-Assisted Quantitative Assessment of Prostatic Calcifications in Patients with Chronic Prostatitis. Urol Int. 2018; 100:450-455.

36. De Visschere PJ, Vral A, Perletti G, et al. Multiparametric magnetic resonance imaging characteristics of normal, benign and malignant conditions in the prostate. Eur Radiol. 2017; 27:2095-2109.

37. Kasivisvanathan V, et al. MRI-Targeted or Standard Biopsy for Prostate-Cancer Diagnosis. N Engl J Med. 2018; 378:1767-1777.

38. Mottet N, van den Bergh RCN, Briers E, et al. Prostate Cancer. EAU Guidelines. Edn. presented at the EAU Annual Congress Copenhagen 2018.

39. Hom JJ, et al. High-grade prostatic intraepithelial neoplasia in patients with prostate cancer: $M R$ and MR spectroscopic imaging features--initial experience. Radiology, 2007; 242:483-9.

40. Sciarra A, et al. Magnetic resonance spectroscopic imaging $(1 \mathrm{H}-$ MRSI) and dynamic contrast-enhanced magnetic resonance (DCEMRI): pattern changes from inflammation to prostate cancer. Cancer Invest, 2010; 28:424-32.

41. Nagel KN, et al. Differentiation of prostatitis and prostate cancer by using diffusion-weighted MR imaging and MR-guided biopsy at $3 \mathrm{~T}$. Radiology. 2013; 267:164-72.

42. Grabe M, Bjerklund-Johansen TE, Botto H, et al Guidelines on urological infections. In: Grabe M, Bjerklund-Johansen TE, Botto $H$, Wullt B, C, ek M, Naber KG, Pickard RS, Tenke P, Wagenlehner F (eds) European Association of Urology Guidelines, 2012,Ch 10.4.1, p 69.

43. Nickel JC. Is chronic prostatitis/chronic pelvic pain syndrome an infectious disease of the prostate? Investig Clin Urol. 2017; 58:149-151.

44. Cai T, et al. Chlamydia trachomatis versus common uropathogens as a cause of chronic bacterial prostatitis: is there any difference?
Results of a prospective parallel-cohort study. Investig Clin Urol. 2017; 58:460-467.

45. Horner PJ, Martin DH. Mycoplasma genitalium infection in men. J Infect Dis 2017;216:S396-405.

46. Horner P, et al. Should we be testing for urogenital Mycoplasma hominis, Ureaplasma parvum and Ureaplasma urealyticum in men and women? - a position statement from the European STI Guidelines Editorial Board. J Eur Acad Dermatol Venereol. 2018; 32:1844-51.

47. Jungwirth A, et al. Guidelines on Male infertility, European Association of Urology, 2016.

48. Manual of Clinical Microbiology, 11th ed, Jorgensen JH and Pfaller MA. 2015, ASM Press, Washington D.C., U.S.A.

49. Miller JM, et al. A guide to utilization of the Microbiology Laboratory for diagnosis of infectious diseases: 2018 update by the Infectious Diseases Society of America and the American Association for Microbiology. Clin Infect Dis. 2018; 67:e1-e94.

50. Mobley DF. Semen cultures in the diagnosis of bacterial prostatitis J Urol. 1975; 114:83-5.

51. Leigh DA. Prostatitis--an increasing clinical problem for diagnosis and management. Antimicrob Chemother. 1993; 32 Suppl A:1-9.

52. Magri V, Wagenlehner FM, Montanari E, et al. Semen analysis in chronic bacterial prostatitis: diagnostic and therapeutic implications. Asian J Androl. 2009; 11:461-77.

53. Nickel JC. Recommendations for the evaluation of patients with prostatitis. World J Urol. 2003;21:75-81.

54. Zegarra Montes LZ, Sanchez Mejia AA, Loza Munarriz CA, Gutierrez EC. Semen and urine culture in the diagnosis of chronic bacterial prostatitis. Int Braz J Urol. 2008; 34:30-7.

55. Budia A, Luis Palmero J, Broseta E, et al. Value of semen culture in the diagnosis of chronic bacterial prostatitis: a simplified method. Scand J Urol Nephrol. 2006; 40:326-31.

56. Bartoletti R, Cai T. Chronic prostatitis and biofilm. Infez Med. 2009; 17:10-16.

57. Mazzoli S. Biofilms in chronic bacterial prostatitis (NIHII) and in prostatic calcifications. FEMS Immunol Med Microbiol. 2010; 59:337344.

58. Bartoletti R, Cai T, Nesi G, et al. The impact of biofilm-producing bacteria on chronic bacterial prostatitis treatment: results from a longitudinal cohort study. World J Urol. 2014; 32:737-42.

59. Cai T, Tessarolo F, Caola I, et al. Prostate calcifications: A case series supporting the microbial biofilm theory. Investig Clin Urol. 2018; 59:187-193.

60. Nickel JC. Perplexing Problem of Persistently Painful Prostatitis Rev Urol. 1999; 1:160-169.

61. Lobel B, Rodriguez A. Chronic prostatitis: what we know, what we do not know, and what we should do! World J Urol. 2003; 21:57-63.

62. Sutcliffe S, Giovannucci E, De Marzo AM, et al. Sexually transmitted infections, prostatitis, ejaculation frequency, and the odds of lower urinary tract symptoms. Am J Epidemiol. 2005; 162:898-906.

63. Panagopoulos P, Antoniadou A, Kanellakopoulou K, et al. Fluoroquinolone treatment of chronic bacterial prostatitis: a prospective cohort study. J Chemother. 2009; 21:317-21.

64. Seo Y, Lee G. Antimicrobial Resistance Pattern in Enterococcus faecalis Strains Isolated From Expressed Prostatic Secretions of Patients With Chronic Bacterial Prostatitis. Korean J Urol. 2013; 54:477-81.

65. Schulz zurWiesch P, Engelstädter J, Bonhoeffer S. Compensation of 
Fitness Costs and Reversibility of Antibiotic Resistance Mutations Antimicrob.Agents Chemother. 2010; 54:2085-2095.

66. Cai T, Mazzoli S, Meacci F,, et al. Epidemiological features and resistance pattern in uropathogens isolated from chronic bacterial prostatitis. J Microbiol. 2011; 49:448-54.

67. Wagenlehner FM, Weidner W, Sörgel F, Naber KG. The role of antibiotics in chronic bacterial prostatitis. Int J Antimicrob Agents. 2005; 26:1-7.

68. Charalabopoulos $K$, Karachalios $G$, Baltogiannis D, et al. Penetration of antimicrobial agents into the prostate. Chemotherapy. 2003; 49:269-279.

69. Perletti G, Marras E, Wagenlehner FM, Magri V. Antimicrobial therapy for chronic bacterial prostatitis. Cochrane Database Syst Rev. 8:CD0090712013.

70. Zhanel GG, Zhanel MA, Karlowsky JA. Oral fosfomycin for the treatment of acute and chronic bacterial prostatitis caused by multidrug-resistant Escherichia coli Can J Infect Dis Med Microbiol. 2018; 2018:1404813.

71. Paglia M, Peterson J, Fisher AC, et al. Safety and efficacy of levofloxacin $750 \mathrm{mg}$ for 2 weeks or 3 weeks compared with levofloxacin $500 \mathrm{mg}$ for 4 weeks in treating chronic bacterial prostatitis. Curr Med Res Opin. 2010; 26:1433-41.

72. Lipsky BA, Byren I, Hoey CT. Treatment of bacterial prostatitis. Clin Infect Dis. 2010; 50:1641-52.

73. Bassetti M, Carnelutti A, Peghin M. Patient specific risk stratification for antimicrobial resistance and possible treatment strategies in gram-negative bacterial infections. Expert Rev Anti Infect Ther. 2017; 15:55-65.

74. Kobayashi I, Ikawa K, Nakamura K, et al. Penetration of piperacillin-tazobactam into human prostate tissue and dosing considerations for prostatitis based on site-specific pharmacokinetics and pharmacodynamics. J Infect Chemother. 2015; 8:575-80.

75. Nishikawa G, Ikawa K, Nakamura K, et al. Prostatic penetration of meropenem in humans, and dosage considerations for prostatitis based on a site-specific pharmacokinetic/pharmacodynamic evaluation. Int J Antimicrob Agents. 2013; 41:267-71.

76. Bates D, Parkins M, Hellweg R, et al. Tigecycline treatment of urinary tract infection and prostatitis: case report and literature review. Can J Hosp Pharm. 2012; 65:209-15.

77. Hampton T. Novel programs and discoveries aim to combat antibiotic resistance. JAMA 2015; 13:24112413.

78. Centers for Disease Control and Prevention, Office of Infectious Disease. Antibiotic resistance threats in the United States, 2013.

79. The Review on Antimicrobial Resistance. Tackling drug resistant infections globally: Final report and recommendations 2016, Chaired by J. O'Neill. WHO. Antimicrobial Resistance: Global Report on Surveillance. Geneva, 2014.

80. Golkar Z, Bagazra O, Pace DG. Bacteriophagy therapy: A potential solution for the antibiotic crisis. J Infect Dev Ctries. 2014; 8:129136.

81. Boucher HW, Talbot GH, Bradley S, et al. Bad bugs, no drugs: No ESKAPE! An update from the Infectious Diseases Society of America. Clin Infect Dis. 2009; 48:112.

82. Barlam TF, Cosgrove SE, Abbo LM, et al. Implementing an antibiotic stewardship program: Guidelines by the Infectious Diseases Society of America and the Society for Healthcare Epidemiology of America. Clin Infect Dis. 2016; 62:e51-77.
83. Schagdarsurengin U, Teuchert LM, Hagenkötter C, et al. Chronic Prostatitis Affects Male Reproductive Health and Is Associated with Systemic and Local Epigenetic Inactivation of C-XC Motif Chemokine 12 Receptor C-X-C Chemokine Receptor Type 4. Urol Int. 2017; 98:89-101.

84. Nesheim N, Ellem S, Dansranjavin T, et al. Elevated seminal plasma estradiol and epigenetic inactivation of ESR1 and ESR2 is associated with CP/CPPS. Oncotarget. 2018; 9:19623-19639.

85. Wagenlehner FM, van Till JW, Magri V, et al. National Institutes of Health Chronic Prostatitis Symptom Index (NIH-CPSI) symptom evaluation in multinational cohorts of patients with chronic prostatitis/chronic pelvic pain syndrome. Eur Urol. 2013; 63:953-9.

86. Wagenlehner FME, van Till JWO, Houbiers JGA, et al. Fatty acid amide hydrolase inhibitor treatment in men with chronic prostatitis/chronic pelvic pain syndrome: an adaptive double-blind, randomized controlled trial. Urology. 2017; 103:191-197.

87. Magri V, Marras E, Restelli A, Wagenlehner FM, Perletti G. Multimodal therapy for category III chronic prostatitis/chronic pelvic pain syndrome in UPOINTS phenotyped patients. Exp Ther Med. 2015; 9:658-666.

88. Cohen JM, Fagin AP, Hariton E, Niska JR, Pierce MW, Kuriyama $A$, et al. Therapeutic intervention for chronic prostatitis/chronic pelvic pain syndrome (CP/CPPS): A systematic review and metaanalysis. PLoS One 2012, 7:e41941.

89. Nickel JC, Pontari M, Moon T, et al. Rofecoxib Prostatitis Investigator Team A randomized,placebo controlled, multicenter study to evaluate the safety and efficacy of rofecoxib in the treatment of chronic nonbacterial prostatitis J Urol. 2003; 169:1401-5.

90. Thakkinstian A, Attia J, Anothaisintawee T, Nickel JC. $\alpha$ Blockers, antibiotics and anti-inflammatories have a role in the management of chronic prostatitis/chronic pelvic pain syndrome. BJU Int. 2012; 110: 1014-22.

91. Magistro G, Wagenlehner FME, Grabe M, et al. Contemporary Management of Chronic Prostatitis/Chronic Pelvic Pain Syndrome. Eur Urol. 2016; 69:286-97.

92. Shoskes DA, Zeitlin SI, Shahed A, Rajfer J. Quercetin in men with category III chronic prostatitis: a preliminary prospective, double-blind, placebo-controlled trial. Urology. 1999; 54:960-3.

93. Wagenlehner FME, Schneider H, Ludwig M, et al. A Pollen Extract (Cernilton) in patients with inflammatory chronic prostatitis-chronic pelvic pain syndrome: a multicentre, randomised, prospective, double-blind, placebo-controlled phase 3 study. Eur Urol. 2009; 56:544-51.

94. Maslowski KM, Mackay CR. Diet, gut microbiota and immune responses. Nat Immunol. 2011; 12:5-9.

95. Willet WC Balancing life-style and genomics research for disease prevention Science. 2002; 296:695-8.

96. Tracy SW Something new under the sun? The Mediterrean Diet and Cardiovascular Health N Eng J Med. 2013; 368:1274-76.

97. Hotamisligil GS Endoplasmic reticulum stress and the inflammatory basis of metabolic disease Cell. 2010b; 140:900-17.

98. Kubes $P$, Mehal WZ Sterile inflammation in the liver Gastroenterology. 2012;.143:1158-72.

99. Gill SR, Pop M, Deboy RT, et al. Metagenomic analysis of the human distal gut microbiome. Science. 2006; 312:1355-9.

100. Kamada N, Chen GY, Inohara N, Núñez G. Control of pathogens and pathobionts by the gut microbiota. Nat Immunol. 2013; 14:685-90. 
101. Owyang C, Wu GD. The gut microbiome in health and disease. Gastroenterology. 2014; 146:1433-6.

102. Bäckhed F, Ley RE, Sonnenburg JL, Peterson DA, Gordon JI. Host-bacterial mutualism in the human intestine. Science. 2005; 307:1915-20.

103. Eckburg PB, Bik EM, Bernstein CN, et al. Diversity of the human intestinal microbial flora. Science. 2005; 308:1635-8.

104. Walker WA. Bacterial colonization, probiotics, and development of intestinal defense. Funct Food Rev. 2009; 1:13-9.

105. Lutgendorff F, Akkermans LM, Söderholm JD. The role of microbiota and probiotics in stress-induced gastrointestinal damage. Curr Mol Med 2008; 8: 282-98.

106. Cario E, Gerken G, Podolsky DK. Toll-like receptor 2 controls mucosal inflammation by regulating epithelial barrier function. Gastroenterology. 2007; 132:1359-13.

107. Louis P, Scott KP, Duncan SH, Flint HJ. Understanding the effects of diet on bacterial metabolism in the large intestine. J Appl Microb 2007; 102: 1197-20

108. Shoskes DA, Wang H, Polackwich AS, et al. Analysis of gut microbiome reveals significant differences between men with chronic prostatitis/chronic pelvic pain syndrome and controls. J Urol. 2016; 196:435-41.

109. Arora HC, Eng C, Shoskes DA. Gut microbiome and chronic prostatitis/chronic pelvic pain syndrome. Ann Trans Med. 2017; 5:30.
110. Guo S, Nighot M, Al-Sadi R, et al. Lipopolysaccharide regulation of Intestinal tight junction permeability is mediated by TLR4 signal transduction pathway activation of FAK and MyD88. J Immunol. 2015; 195:4999-5010.

111. Fasano A, Not T, Wang W, et al. Zonulin, a newly discovered modulator of intestinal permeability, and its expression in coeliac disease. Lancet. 2000; 355:1518-9.

112. Ravel J, Gajer P, Abdo Z, et al. Vaginal Microbiome of reproductive-age women. Proc Natl Acad Sci U S A. 2011; 108 Suppl 1:4608-7.

113. Lepargneur JP, Rousseau V. Protective role of the Doderlein flora j.Gynecol Obstet Biol Reprod. 2002; 31:485-94.

114. The vaginal microenvironment: the physiologic role of lactobacilli. Academic Unit of Reproductive and Developmental Medicine, University of Sheffield, Sheffield, United Kingdom, 2018.

115. Unemo M, Bradshaw CS, Hocking JS, et al. Sexually transmitted infection: challenges ahead. Lancet Infect Dis. 2017; 17: e235-e279.

116. Gruppo multidisciplinare "Malattie infettive in ostetricia ginecologia e neonatologia" AMCLI-SIGO-SIMAST-SIMIT-SIN-SIP - Raccomandazioni, 2014.

117. Vitali B, Cruciani F, Picone G, et al. Vaginal microbiome and metabolome highlight signatures of bacterial vaginosis. Eur J Clin Microbiol Infect Dis. 2015, 34:2367-76.

\section{Correspondence}

Vittorio Magri, MD

vittorio.magri@virgilio.it

Urology - ASST Nord Milano, Milan, Italy

Matteo Boltri, MD

matteo.boltri@gmail.com

Urology Medical School, University of Trieste, Trieste, Italy

Tommaso Cai, MD

ktommy@libero.it

Department of Urology,Santa Chiara Regional Hospital, Trento, Italy

Roberto Colombo, $\mathrm{MD}$

roberto.colombo@synlab.it

Synlab Italia Srl Via Beato Lodovico Pavoni 18, 25014 Castenedolo (BS)

Salvatore Cuzzocrea, MD

salvatore.cuzzocrea@unime.it

Università degli Studi di Messina, Messina, Italy

Pieter De Visschere, MD, PhD

pieter.devisschere@ugent.be

Department of Radiology and Nuclear Medicine, Ghent University Hospital, Ghent, Belgium

Gaetano Larganà, MD

Giuseppe Morgia, MD

gmorgia@policlinico.unict.it

Departmento of Urology, Università degli Studi di Catania, Catania, Italy

Rosanna Giuberti, MD

giuroti@gmail.com

SICT Società Idrocolonterapia, Milan, Italy

Clara Maria Granatieri, MD

clara.granatieri@gmail.com

Internal Medicine, ASST Nord Milano, Milan, Italy 
Maria Agnese Latino maglatino@gmail.com

Alessandra Sensini, MD

alessandrasensini@yahoo.it

Working Group on Sexually Transmitted Infections - Italian Association of Clinical Microbiologists, GLIST-AMCLI

Christian Leli, MD

Unit of Microbiology, SS Antonio, Biagio and C. Arrigo Hospital, Alessandria, Italy.

Giorgio Maierna, MD

giorgio.maierna@asst-nordmilano.it

Quality and Risk Management - ASST Nord Milano, Milan, Italy

Valentina Marchese, $M D$

v.marchese@unibs.it

Alberto Matteelli, MD

Department of Infectious and Tropical Diseases, University of Brescia, Piazzale Spedali Civili, 25123, Brescia, Italy

Elisabetta Massa, MD

empmassa@gmail.com

Gynaecology - ASST Nord Milano, Milan, Italy

Emanuele Montanari, MD

emanuele.montanari@unimi.it

Department of Urology, IRCCS Ca’ Granda Ospedale Maggiore Policlinico - University of Milan, Milan, Italy

Kurt G, Naber, MD, PhD

kurt@nabers.de

Assoc. Professor of Urology - Technical University of Munich, Munich, Germany -Karl-Bickleder-Str. 44c, 94315 Straubing, Germany

Vaia Papadouli, MD

Nektaria Rekleiti, $M D$

nekrek@gmail.com

Microbiology Department, Tzaneion Hospital, Piraeus, Greece

Gianpaolo Perletti, PhD

gianpaolo.perletti@uninsubria.it

Department of Biotechnology and Life Sciences, Section of Medical and Surgical Sciences,University of Insubria, Varese, Italy

Giorgio I. Russo, MD

giorgioivan1987@gmail.com

Department of Urology, Università degli Studi di Catania

Konstantinos Stamatiou, MD

stamatiouk@gmail.com

Urology Department, Tzaneio Hospital, Piraeus, Greece

Alberto Trinchieri, MD (Corresponding Author)

alberto.trinchieri@gmail.com

Urology Unit, Manzoni Hospital, Lecco, Italy

Florian ME Wagenlehner, MD

florian.wagenlehner@chiru.med.uni-giessen.de

Clinic for Urology, Pediatric Urology and Andrology - Justus Liebig University Giessen, Germany 